\title{
How Much of the Corporate-Treasury Yield Spread is Due to Credit Risk? ${ }^{1}$
}

\author{
Jing-zhi Huang \\ Pennsylvania State University \\ and \\ Ming Huang \\ Stanford University
}

This draft: October, 2002

\footnotetext{
${ }^{1}$ We thank Nick Barberis, Pierre Collin-Dufresne, Greg Duffee, Darrell Duffie, Amit Goyal, Jean Helwege, Alfredo Ibáñez, Stephen Schaefer, Ken Singleton, Suresh Sundaresan, Sheridan Titman, and participants at the Berkeley-Stanford joint seminar, the Texas Finance Festival, MIT finance seminar, and the 2002 C.R.E.D.I.T. conference for valuable comments. This paper was previously entitled "How Much of the Corporate-Treasury Yield Spread is Due to Credit Risk? A New Calibration Approach." J. Huang is at Smeal College of Business, Penn State University, University Park, PA 16802; Email: jxh56@psu.edu. M. Huang is at Graduate School of Business, Stanford University, Stanford, CA 94305; Email: mhuang@stanford.edu. For the most recent version of the paper, please visit http://www.stanford.edu/ ${ }^{\sim}$ mhuang/.
} 


\title{
How Much of the Corporate-Treasury Yield Spread Is Due to Credit Risk?
}

\begin{abstract}
We show that credit risk accounts for only a small fraction of the observed corporateTreasury yield spreads for investment grade bonds of all maturities, with the fraction smaller for bonds of shorter maturities; and that it accounts for a much higher fraction of yield spreads for junk bonds. This conclusion is shown to be robust across a wide class of structural models - both existing and new ones - that incorporate many different economic considerations. We obtain such consistent results by calibrating each of the models to be consistent with data on historical default loss experience. Different models, which in theory can still generate a very large range of credit risk premia, are shown to predict fairly similar credit risk premia under empirically reasonable parameter choices, resulting in the robustness of our conclusion.
\end{abstract}




\section{Introduction}

Corporate bonds typically trade at higher yields than Treasury bonds of comparable maturities. The yield spread is partly due to the credit risk of corporate bonds, and is thus frequently referred to as the "credit spread." Credit risk, however, is only one of the factors contributing towards the corporate-Treasury yield spread; other factors include illiquidity, call and conversion features of some corporate bonds, and asymmetric tax treatments of corporate and Treasury bonds. In this paper, we ask how much of the corporate-Treasury yield spread is actually attributable to credit risk. This question is important to research and practice on credit risk. It is also important because its resolution can help us understand how well the corporate bond and equity markets are integrated, which has implications for the theory of capital structure. ${ }^{1}$

Any attempt to address this question needs to start from a theoretical framework on how credit risk should be priced. ${ }^{2}$ One of the most widely employed frameworks of credit risk valuation is the structural approach pioneered by Black and Scholes (1973) and Merton (1974), and subsequently extended by many researchers over the last few decades. ${ }^{3}$ This approach treats a firm's equity and debt as contingent claims on its asset value. We conduct our analysis within this framework as well. ${ }^{4}$

\footnotetext{
${ }^{1}$ See Titman (2002) for a recent review of the effect of market segmentation on capital structure theory.

${ }^{2}$ This creates a joint hypothesis problem. When a calculated credit yield spread based on a credit-risk model fails to match the empirically observed corporate-Treasury yield spread, some may conclude that the model is wrong. This conclusion, however, relies on an implicit assumption that all of the corporate-Treasury yield spread should be due to credit risk. In this paper, we take the view that credit risk is only one of the factors behind the corporate-Treasury yield spread, and prefer to interpret the calculated credit yield spread as the part of the observed yield spread attributable to credit risk, at least according to existing theories.

${ }^{3} \mathrm{~A}$ partial list of theoretical extensions within this framework includes Anderson and Sundaresan (1996), Black and Cox (1976), Collin-Dufresne and Goldstein (2001), Duffie and Lando (2001), Geske (1977), Kim, Ramaswamy, and Sundaresan (1993), Leland (1994, 1998), Leland and Toft (1996), Longstaff and Schwartz (1995), Mella-Barral and Perraudin (1997), Nielsen, Saa-Requejo, and Santa-Clara (1993), and Zhou (2001).

${ }^{4}$ Another widely used framework of credit risk valuation is the reduced-form approach (see, for example, Jarrow and Turnbull (1995) and Duffie and Singleton (1999)). This framework, however, is designed to take prices of corporate bonds as inputs and is therefore not well-suited for answering our question.
} 
Many previous studies within the structural framework have also analyzed how much of the observed corporate-Treasury yield spread can be explained by credit risk, but so far, no consensus has emerged from these studies.

Most of the controversy focuses on medium- and long-maturity bonds. While many studies, including the early work by Jones, Mason, and Rosenfeld (1984), have shown that the credit yield spreads predicted by the original Merton (1974) model are far below the empirically observed corporate-Treasury yield spreads, others have argued that extensions of the Merton model within the structural framework that incorporate certain realistic economic considerations can fully explain the observed yield spreads (at least for bonds with long enough maturities). For example, ${ }^{5}$ Anderson and Sundaresan (1996) and Anderson, Sundaresan, and Tychon (1996) have argued that incorporating strategic default by equity holders who try to extract concessions from bondholders can explain why corporate-Treasury credit spreads should be high (see also Mella-Barral and Perraudin (1997)); Collin-Dufresne and Goldstein (2001) have argued that firms with good credit quality are likely to issue more debt, which leads to credit spreads that are comparable to the observed high yield spreads for long-maturity bonds issued by such firms; Longstaff and Schwartz (1995) (with an analytically tractable model incorporating bankruptcy costs, the violation of absolute priority rule, and stochastic interest rates), and Leland (1994, 1998) and Leland and Toft (1996) (with models of endogenous default) have also shown that structural models are capable of generating a large range of credit spreads that spans the observed corporate yield spreads.

Even for short-maturity bonds, it is arguable that no clear consensus exists. While studies using structural models based on diffusion-type firm value processes conclude that credit risk cannot possibly explain the observed corporate yield spreads, considerations such as incomplete accounting information (Duffie and Lando (2001)) and jumps in asset value (Zhou (2001)) are shown to generate high credit spreads.

Empirically, recent direct tests of structural models conducted by Anderson and Sundaresan (2000), Lyden and Saraniti (2000), and Eom, Helwege, and Huang (2002) show mixed results on the ability of structural models to explain observed corporate

\footnotetext{
${ }^{5}$ Of course, all of the following theoretical models, as well as other theoretical extensions of the Merton approach that we mention in this paper, are primarily focused on the interesting effects of various realistic economic considerations on credit risk valuation, and therefore contribute to the literature far more than their calculated credit spreads, which happens to be the focus of our paper.
} 
yield spreads.

In this paper, we show that a fairly strong consensus on the quantitative magnitude of credit yield spreads can be reached within the structural framework. The key to our approach is to require that models within the structural framework confront the available historical data on bond default. So far, with the exception of KMV (see Kealhofer and Kurbat (2001)) and a recent study by Leland (2002), few studies have systematically compared the expected level of default loss - both the default probability and the loss rate given default - predicted by structural models to the observed historical default loss experience, despite the fact that the perceived severity of potential default loss is clearly important to bondholders and that structural models are fully capable of making predictions about expected levels of default loss, in addition to predictions of bond prices and yields.

We show that a large class of structural models - both existing and new onesthat incorporate many realistic economic considerations can indeed generate very consistent credit yield spreads if each of the models is calibrated to match historical default loss experience data. The robustness of results under our calibration approach allows us to conclude that, for investment grade bonds (those with a credit rating not lower than Baa) of all maturities, credit risk accounts for only a small fractiontypically around 20\%, and, for Baa-rated 10-year bonds, in the $30 \%$ range - of the observed corporate-Treasury yield spreads, and it accounts for a lower fraction of the observed spreads for bonds of shorter maturities. For junk bonds, however, credit risk accounts for a much larger fraction of the observed corporate-Treasury yield spreads.

Our work is not the first to emphasize that historical default experience datacollected and studied carefully over many years by Altman (2001), Moody's, Standard and Poor's, and others - should be important in our attempt to understand credit risk pricing. Outside of the structural framework, Fons (1994) has used statistical methods to understand the implication of default data on the term structure of credit yield spreads, and Elton, Gruber, Agrawal, and Mann (2001) also made use of default loss data in their study of different components of corporate-Treasury yield spreads. One common finding from these studies is that the average historical default loss rate for corporate bonds is typically much smaller than the observed corporate-Treasury yield spreads, and is only a small fraction of the yield spreads for investment-grade bonds. Figure 1 provides a visual summary of this finding.

This fact alone, however, should not lead one to automatically conclude that credit 
risk accounts for only a small fraction of the observed yield spreads for investment grade bonds. After all, the expected default loss rate is only part of the (promised) credit yield spread; the other part is the credit risk premium, defined as the difference between the expected realized return of a defaultable bond and that of a Treasury security with a comparable maturity. The credit risk premium is required by investors because the uncertainty of default loss should be systematic - bondholders are more likely to suffer default losses in bad states of the economy. Moreover, precisely because of the tendency for default events to cluster in the worst states of the economy, the credit risk premium can be potentially very large. In fact, some of the models considered in this paper can indeed generate credit risk premia that are large enough to explain the difference between the observed corporate yield spreads and historical default loss rate, provided that certain parameter choices are made. The key question, however, is whether any model can generate such large credit risk premia under empirically reasonable parameter choices. This question is the main focus of our paper.

The structural approach to credit risk valuation offers a natural and appealing theoretical framework for understanding the credit risk premium. This approach, based on the contingent-claim analysis method, does not require that we have an accurate theory of the source of asset or equity premium in most of its applications. An alternative approach to estimating the credit risk premium, adopted by Elton, Gruber, Agrawal, and Mann (2001), is to use linear regressions of bond returns on empirically identified Fama-French factors. Such an approach is appealing in its simplicity and allows for easy comparison with the literature on equity returns, but it does rely on the theoretical, not just empirical, accuracy of the Fama-French factors as drivers of the equity risk premium. In addition, such an approach may not be able to separate out the credit risk premium from other components of systematic risk premia in corporate bond returns, such as premia due to liquidity risk or embedded options in corporate bonds. For these reasons, we choose to conduct our analysis in the structural framework. This has the additional benefit that we can make use of the richness of structural models to analyze the effects of many economic assumptions on the credit risk premium.

The structural models that we study in this paper represent a cross section of economic assumptions. They include Longstaff and Schwartz (1995) (with stochastic interest rates), Leland and Toft (1996) (with endogenously determined default 
boundaries), Anderson and Sundaresan (1996), Anderson, Sundaresan, and Tychon (1996), and Mella-Barral and Perraudin (1997) (with strategic defaults), and CollinDufresne and Goldstein (2001) (with mean-reverting leverage ratios policy). These models, however, may not adequately capture the intuition that the credit risk premium can be potentially very high if we consider the fact that some special states of the economy associated with high default probabilities may also require high market risk premia. In order to investigate the validity of such intuition, we study two mechanisms through which the existence of such states may lead to high credit risk premia. First, we consider a credit risk model with a counter-cyclical market risk premium to capture the effects of business cycles on credit risk premia. Secondly, we introduce an analytically tractable jump-diffusion structural credit risk model to capture the effects on credit risk premia of certain future states with both high default risks and abnormally high stochastic discount factors. We show that, under empirically reasonable parameter choices, our conclusion remains robust across all of these models.

The main difference between our paper and previous applications of structural models to the calculation of credit yield spreads is that we calibrate all models to match historical bond default experience data (both default frequencies and loss rates given default), in addition to matching data that other studies also made use of, such as balance sheet information and equity return data. The disadvantage of our approach is that we do not explore - from first principles - the effects of various economic assumptions on the default probability or the recovery rate given default, although our approach fully takes into account such effects. Recent work by Leland (2002) on the implication of structural models on default probabilities provides a nice complement to our work in this regard. The advantage of our approach, however, is that it allows us to reach robust conclusions regarding the quantitative magnitude of credit yield spreads by using models that are consistent with the actual severity of the expected default loss. In addition, it allows us to analyze whether discrepancies among previous calculations of credit yield spreads are due to differences in predicted default loss rates or in predicted credit risk premia. For example, our results suggest that some previous claims that credit risk can explain all of the observed investment-grade corporate yield spreads may be based on models that would predict counterfactually high default loss rates.

Some other studies are also related to our work. Delianedis and Geske (2001) 
study the relative importance of different components for corporate yield spreads, but they do not focus on historical default experience data as we do. Collin-Dufresne, Goldstein, and Martin (2001) and Campbell and Taksler (2002) study whether economic variables that may determine default risk can explain the time variation in corporate-Treasury yield spreads, with the former paper showing that credit-riskrelated variables can explain only a small portion of corporate-Treasury yield spread movements.

The rest of the paper is organized as follows. Section 2 briefly outlines the class of structural models that we consider, including a new jump-diffusion model that we will introduce; section 3 describes our calibration method; section 4 presents and discusses our calibration results from various models; and section 5 concludes.

\section{Existing and New Structural Models}

We study a large class of structural models, which include many existing models. We also introduce a model with a time-varying risk premium, and a new jump-diffusion structural model. For completeness, we briefly outline all of the models that we will consider in this paper. These models combine to give a reasonable representation of the cross section of all structural models.

All models that we consider share the following common general structure:

- Firm value process: most of the existing structural models assume that the firm asset value evolves according to a diffusion process with a constant volatility:

$$
d V_{t}=\left(\pi_{t}^{v}+r_{t}-\delta_{t}\right) V_{t} d t+\sigma_{v} V_{t} d W_{t}^{v},
$$

where $r_{t}$ is the riskfree interest rate, $\pi_{t}^{v}$ is the asset risk premium, $\delta_{t}$ is the rate at which cash is paid out to the firm's investors (bondholders and stockholders), as a fraction of the firm asset value, and $\sigma_{v}$ is the volatility of the firm's asset value process. Both $r_{t}$ and $\pi_{t}^{v}$ can be either deterministic or stochastic. As usual, $W^{v}$ denotes a standard Brownian motion under the real probability measure.

In the risk neutral measure $Q$, the firm value process can be written as

$$
d V_{t}=\left(r_{t}-\delta_{t}\right) V_{t} d t+\sigma_{v} V_{t} d W_{t}^{v Q}
$$


where $W^{v Q}$ is a standard Brownian motion under the risk-neutral probability measure.

In addition, we will also consider modeling the firm's asset value as a jumpdiffusion process, which we will specify when we introduce the jump-diffusion credit risk model later on.

- Default boundary: default occurs when the firm value $V_{t}$ falls to or below the level of $V_{t}^{*}$ for the first time. That is, default occurs at $\tau=\min \left\{t: V_{t} \leq V_{t}^{*}\right\}$. The default boundary $\left\{V_{t}^{*}\right\}$ can be deterministic or stochastic, exogenously specified or endogenously derived.

- Default recovery rule: at default, bondholders receive a payoff of $\Pi\left(V_{\tau}, F\right)$, where $F$ denotes the face value of the bond.

The time- $t$ market value of a bond issued by the firm and maturing at $T, P_{t, T}$, can be calculated using the risk-neutral pricing method, which typically requires the assumption that the assets of the firm can be traded. For the class of models that we consider in this paper, we have:

$$
P_{t, T}=P\left(V_{t}, \sigma_{v}, r_{t}, \Theta\right)
$$

where $\Theta$ denotes a vector of additional structural parameters in the model such as the default recovery rate and parameters related to the jump and interest-rate processes.

This class of models also generate quantitative predictions of default probabilities (or expected default frequencies (EDFs)) for bonds. The firm value process under the real measure, shown in equation (1), and the default boundary specification allow us to obtain the real-world default probabilities. Let $\operatorname{Pr}(t, T)$ denote the cumulative real default probability over the time interval $(t, T]$ calculated based on information available at time $t$. We have

$$
\operatorname{Pr}(t, T)=\operatorname{Pr}\left(V_{t}, \sigma_{v}, r_{t}, \pi_{t}^{v}, \Theta\right)
$$

Note that the real default probability depends on the risk premium associated with the firm's asset, while the bond price does not.

In this paper, we will study the following structural models: the two-factor model of Longstaff and Schwartz (1995) (referred to as LS), the strategic default models of Anderson and Sundaresan (1996), Anderson, Sundaresan, and Tychon (1996), 
and Mella-Barral and Perraudin (1997) (collectively referred to as AST-MBP), the endogenous-default models of Leland (1994) and Leland and Toft (1996) (collectively referred to as LT), the stationary leverage model of Collin-Dufresne and Goldstein (2001) (referred to as CDG). We also introduce a model with a time-varying asset risk premium, and a model with a jump-diffusion firm value process.

Undoubtedly, the list of models that we consider misses some important structural models. We choose these models because they collectively deal with some of the main economic considerations involved in credit risk valuation within the structural framework while maintaining analytical tractability. ${ }^{6}$

We next briefly review the existing models (for completeness) and introduce new ones. While each of the existing models was developed to address certain interesting economic issues on credit risk, our review here focuses only on the technical setup of such models for the purpose of credit risk valuation. Readers may wish to skip the discussions of model(s) that are familiar to them.

\section{Longstaff and Schwartz (1995) (LS)}

In the LS model, the interest rate is stochastic and is described by the Vasicek (1977) model under the risk-neutral measure:

$$
d r_{t}=\kappa_{r}\left(\theta-r_{t}\right) d t+\sigma_{r} d W_{t}^{r Q}
$$

where $\kappa_{r}, \theta$, and $\sigma_{r}$ are constant parameters, and $W^{r Q}$ is a standard Brownian motion under the risk-neutral measure with a constant correlation with $W^{v Q}$ denoted as $\rho_{r V}$. For the interest rate process under the real probability measure, we follow convention and assume that the interest rate risk premium is of an affine form in $r_{t}$, such that

$$
d r_{t}=\bar{\kappa}_{r}\left(\bar{\theta}-r_{t}\right) d t+\sigma_{r} d W_{t}^{r}
$$

where $\bar{\kappa}_{r}$ and $\bar{\theta}$ are constant parameters, and $W^{r}$ is a standard Brownian motion under the real probability measure.

The default boundary $\left\{V_{t}^{*}\right\}$ is exogenously specified to be constant. In the event of default, bondholders receive cash flows according to the original time schedule, but

\footnotetext{
${ }^{6}$ Two models notably absent are the original Merton (1974) model and the Geske (1977) model. We choose not to include Merton (1974) because it cannot easily deal with multi-year bond coupons and does not provide the possibility of default before maturity. We did, however, apply our calibration approach to the Merton model, and the results are consistent with those from other models considered here. We omit the Geske (1977) model because it is less analytically tractable.
} 
each payment, which is now received with certainty, is only a fraction of the originally promised amount.

In the original LS model, the payout parameter $\delta_{t}$ is assumed to be zero. Here we consider a more general case where $\delta_{t}=\delta$ can be greater than zero. This allows for a net cash outflow-beyond the amount raised from securities issuance - that is required for the firm to pay bond coupons and dividends.

The asset risk premium $\pi_{t}^{v}$ is assumed to be constant in this version of the model. We will later introduce a model that incorporates a time-varying asset risk premium.

The formula for the real cumulative default probability $\operatorname{Pr}(t, T)$ for the case of constant $\pi_{t}^{v}$ can be found in Appendix A. The formulas for the bond price $P_{t, T}$ can be found in Appendix B.

\section{Anderson-Sundaresan-Tychon (1996) and Mella-Barral and Perraudin (1997) (AST-MBP)}

In the AST-MBP models, equity holders default strategically to extract concessions from bondholders in an environment of positive bankruptcy costs. The default boundary and the payoff given default are obtained endogenously. If equity holders have all the bargaining power, then at the endogenously determined default boundary, the payoff for bondholders will be equal to the firm asset value minus the bankruptcy costs, bounded above by the face value of the bond.

The interest rate $r_{t}$, the asset payout rate $\delta_{t}$, and the asset risk premium $\pi_{t}^{v}$ are all constant.

For the simple case of a perpetual constant flow coupon bond, under the assumption that the bankruptcy costs are a constant fraction $(1-w)$ of the firm value plus a fixed cost of $K$, the default boundary is constant at:

$$
V_{A S T-M B P}^{*}=\frac{c F / r+K}{w\left(1+x^{-1}\right)}
$$

where $c$ is the coupon flow rate and $x$ is defined as

$$
x \equiv \frac{r-\delta}{\sigma_{v}^{2}}-\frac{1}{2}+\left[\left(\frac{r-\delta}{\sigma_{v}^{2}}-\frac{1}{2}\right)^{2}+\frac{2 r}{\sigma_{v}^{2}}\right]^{1 / 2} .
$$


The value of the perpetual bond is

$$
B_{\mathrm{AST}-\mathrm{MBP}}(t)=\frac{c F}{r}\left[1-\left(\frac{V_{t}}{V_{\mathrm{AST}-\mathrm{MBP}}^{*}}\right)^{-x}\right]+\max \left(w V_{\mathrm{AST}-\mathrm{MBP}}^{*}-K, 0\right)\left(\frac{V_{t}}{V_{\mathrm{AST}-\mathrm{MBP}}^{*}}\right)^{-x} .
$$

Assuming that the asset risk premium $\pi_{t}^{v}=\pi^{v}$ is constant, then the cumulative real default probability over $(t, t+\tau]$, calculated with information available at $t$, is given by

$$
\operatorname{Pr}_{\mathrm{AST}-\mathrm{MBP}}(t, t+\tau)=N\left(-\frac{b+\gamma \tau}{\sigma_{v} \sqrt{\tau}}\right)+e^{-\frac{2 \gamma b}{\sigma_{v}^{2}}} N\left(\frac{-b+\gamma \tau}{\sigma_{v} \sqrt{\tau}}\right)
$$

where $b=\ln \left(V_{t} / V_{\mathrm{AST}-\mathrm{MBP}}^{*}\right), \gamma=\pi^{v}+r-\delta-\sigma_{v}^{2} / 2$, and $N(\cdot)$ denotes the cumulative standard normal function.

\section{Leland (1994) and Leland and Toft (1996) (LT)}

The LT model, following Black and Cox (1976), assumes that firms would issue equity to service debt in order to avoid default, and that default occurs when the value of equity goes to zero. This allows for the default boundary to be determined endogenously. In the event of default, equity holders get nothing and bondholders receive a constant fraction $(1-w)$ of the firm asset value, with $w$ denoting the fractional bankruptcy costs.

The interest rate $r_{t}$, the asset payout rate $\delta_{t}$, and the asset risk premium $\pi_{t}^{v}$ are all constant.

As in AST-MBP, for analytic tractability, firms in (a simplified version of) the LT model have a perpetual bond outstanding with a constant coupon flow. ${ }^{7}$

Under the simplifying assumption that the fixed portion of the bankruptcy costs, $K$, is zero, the endogenous default boundary is given by

$$
V_{\mathrm{LT}}^{*}=\frac{c F}{r} \frac{1}{1+x^{-1}}
$$

where $x$ is as defined in (8).

The formulas for the value of the debt and for the real default probability (under the assumption of a constant asset risk premium) in the LT model take the same

\footnotetext{
${ }^{7}$ Leland and Toft (1996) also provide a valuation model for annuity-like debt. We use the simpler perpetuity case here for ease of comparison with other models.
} 
form as those in AST-MBP (as in (9) and (10)), except that $V_{\mathrm{AST}-\mathrm{MBP}}^{*}$ is replaced by $V_{\mathrm{LT}}^{*}$.

\section{Collin-Dufresne and Goldstein (2001) (CDG)}

The CDG model assumes that firms adjust their outstanding debt levels in response to changes in firm value, which makes the stochastic leverage ratio mean-

reverting. The structure of the model is similar to that of the Longstaff-Schwartz model, but the key difference is that the default boundary $V_{t}^{*}$ in CDG is assumed to be mean-reverting according to:

$$
d \ln V_{t}^{*}=\kappa_{l}\left(\ln V_{t}-\ln V_{t}^{*}-\nu\right) d t .
$$

For the case of a constant interest rate, the "log-leverage ratio" $\ell_{t} \equiv \ln \left(V_{t}^{*} / V_{t}\right)$ follows

$$
d \ell_{t}=\kappa_{l}\left(\bar{\ell}-\ell_{t}\right) d t-\sigma_{v} d W_{t}^{v}
$$

where the "long-run average leverage ratio" $\bar{\ell}$ is related to other parameters through

$$
\bar{\ell} \equiv \frac{-\left(\pi^{v}+r\right)+\delta+\sigma_{v}^{2} / 2}{\kappa_{l}}-\nu .
$$

In equation (14), $\delta_{t}$, the asset payout rate, and $\pi_{t}^{v}$, the asset risk premium, are both taken to be constant. As in LS, CDG also allows for the interest rate to be stochastic as described by the Vasicek (1977) model (see (5)).

The formulas for the bond price $P_{t, T}$ and the real cumulative default probability $\operatorname{Pr}(t, T)$ can be found in the appendix.

\section{A Model with a Counter-Cyclical Asset Risk Premium}

Previous studies using the above structural models typically did not need to give an explicit specification of the asset risk premium process, as they focused primarily on the market prices of corporate bonds, which can be calculated using the riskneutral pricing method. Despite our assumption of a constant asset risk premium above, these models can easily accommodate a time-varying asset risk premium. This analytic flexibility turned out to be useful for our study.

A major focus of our paper is the credit risk premium. This is related to the fact that our calibration approach emphasizes the need to compare the prediction of structural models with real world default data. These considerations require that 
we use an empirically reasonable model for the asset risk premium $\pi_{t}^{v}$ process. As we will discuss later, such a model can capture the potential effects of the cyclical variation of market risk premia on credit risk premia. Indeed, many empirical studies have shown that the expected aggregate equity market excess return is time-varying and predictable (see Campbell, Lo, and MacKinlay (1997) for a textbook treatment). Time variation and predictability of the aggregate equity market risk premium implies that individual stock risk premia should also be time-varying and predictable (see Vuolteenaho (2002) for some evidence).

We consider a model with the following dynamic process for the asset risk premium:

$$
d \pi_{t}^{v}=\kappa_{\pi}\left(\bar{\pi}^{v}-\pi_{t}^{v}\right) d t+\sigma_{\pi} d W_{t}^{\pi},
$$

where $\kappa_{\pi}, \bar{\pi}^{v}$, and $\sigma_{\pi}$ are constant parameters, and $W^{\pi}$ is a standard Brownian motion under the real probability measure, which has a correlation coefficient of $\rho_{\pi V}$ with the firm value process. Later, we will discuss how to fit the parameters according to existing studies of equity premium predictability.

For analytic tractability and ease of comparison, we follow the Longstaff-Schwartz model in making all other assumptions, such as the default boundary and the default recovery rule. Such a credit risk model, which effectively extends the LS model to allow for a time-varying asset risk premium, fortunately allows for an analytic solution for the real cumulative default probability.

The formulas for the bond price $P_{t, T}$ and the real cumulative default probability $\operatorname{Pr}(t, T)$ in this extended model are shown in the appendix.

\section{A New Tractable Model with a Double-Exponential Jump-Diffusion Asset Value Process}

The structural models reviewed so far all assume that the firm asset value evolves as a diffusion process with a constant volatility. This approach allows for analytic tractability, but it may not be realistic. Firm value may change suddenly and unexpectedly in a way that is best modeled as a jump. More importantly, we will later discuss how incorporating jumps into the firm value process can capture the potential

effects of some future states with both high default risks and high stochastic discount factors.

But very few studies within the structural approach of credit risk valuation have incorporated jumps in the firm value process, because of lack of analytic tractability. 
The original Merton model - of firms with a simplified capital structure composed of equity and a zero-coupon bond - can certainly allow for jumps in the firm value process, but this model cannot be easily applied to the valuation of coupon bonds and does not allow for default before maturity, which is not realistic. Zhou (2001) incorporated jump risk into a structural credit risk model with coupon bonds, but his solution is numerical (using Monte Carlo simulations) and it would be difficult for us to apply our calibration method to his pricing method. Delianedis and Geske (2001) studied a close variant of the the original Merton (1974) model to allow for jumps in the firm value process, but the model again cannot be applied to coupon bonds and does not allow for default before maturity.

Here, we propose a new structural credit risk model with a jump-diffusion asset value process which allows for analytically tractable solutions for both bond prices and default probabilities. The analytic tractability is made possible by the recent mathematical work of Kou and Wang (2002) who solved for the probability distribution of the first passage time to flat boundaries of a certain kind of double-exponential jump diffusion process.

In this new credit risk model, the firm value process is assumed to evolve, under the real probability measure, according to

$$
\frac{d V_{t}}{V_{t-}}=\left(\pi^{v}+r-\delta\right) d t+\sigma_{v} d W_{t}^{v}+d\left[\sum_{i=1}^{N_{t}}\left(Z_{i}-1\right)\right]-\lambda \xi d t
$$

where the interest rate $r$, firm payout ratio $\delta$, diffusion volatility $\sigma_{v}$ are all constant, $W^{v}$ is a standard Brownian motion, $N$ is a Poisson process with a constant intensity $\lambda>0$, the $Z_{i}$ 's are i.i.d. random variables, and $Y \equiv \ln \left(Z_{1}\right)$ has a double-exponential distribution with a density given by

$$
f_{Y}(y)=p_{u} \eta_{u} e^{-\eta_{u} y} \mathbf{1}_{\{y \geq 0\}}+p_{d} \eta_{d} e^{\eta_{d} y} \mathbf{1}_{\{y<0\}}
$$

In equation (17), parameters $\eta_{u}, \eta_{d}>0$ and $p_{u}, p_{d} \geq 0$ are all constants, with $p_{u}+p_{d}=$ 1. The mean percentage jump size $\xi$ is given by

$$
\xi=\mathbf{E}\left[e^{Y}-1\right]=\frac{p_{u} \eta_{u}}{\eta_{u}-1}+\frac{p_{d} \eta_{d}}{\eta_{d}+1}-1
$$

With such a jump-diffusion firm value process, there exist infinitely many risk neutral probability measures under which the values of the firm's asset, equity, and 
bond - measured with a money market account value as the numeraire - are martingales. For now, we will assume a simple risk-neutral process for the firm asset value. Later in the paper, we will discuss why such a process is reasonable in an equilibrium context and sufficient for our calibration approach, and establish the link between the real probability measure and the risk neutral probability measure.

We assume that, under a risk-neutral measure, the firm's asset value process evolves according to

$$
\frac{d V_{t}}{V_{t-}}=(r-\delta) d t+\sigma_{v} d W_{t}^{v Q}+d\left[\sum_{i=1}^{N_{t}^{Q}}\left(Z_{i}^{Q}-1\right)\right]-\lambda^{Q} \xi^{Q} d t,
$$

where $W^{v Q}$ is a standard Brownian motion, $N^{Q}$ is a Poisson process with a constant intensity $\lambda^{Q}>0$, the $Z_{i}^{Q}$,s are i.i.d. random variables, and $Y^{Q} \equiv \ln \left(Z_{1}^{Q}\right)$ has a double-exponential distribution with a density given by

$$
f_{Y^{Q}}(y)=p_{u}^{Q} \eta_{u}^{Q} e^{-\eta_{u}^{Q} y} \mathbf{1}_{\{y \geq 0\}}+p_{d}^{Q} \eta_{d}^{Q} e^{\eta_{d}^{Q} y} \mathbf{1}_{\{y<0\}} .
$$

In equation (20), parameters $\eta_{u}^{Q}, \eta_{d}^{Q}>0$ and $p_{u}^{Q}, p_{d}^{Q} \geq 0$ are all constants, with $p_{u}^{Q}+p_{d}^{Q}=1$. The mean percentage jump size $\xi^{Q}$ (under the risk-neutral measure) is given by

$$
\xi^{Q}=\mathbf{E}^{Q}\left[e^{Y^{Q}}-1\right]=\frac{p_{u}^{Q} \eta_{u}^{Q}}{\eta_{u}^{Q}-1}+\frac{p_{d}^{Q} \eta_{d}^{Q}}{\eta_{d}^{Q}+1}-1 .
$$

Finally, the jump risk premium - the part of total risk premium $\pi^{v}$ which is due to jump risk-is given by $\lambda \xi-\lambda^{Q} \xi^{Q}$.

For analytic tractability, the default trigger mechanism and default recovery rule are assumed to be the same as those in the Longstaff-Schwartz model. The analytic solutions for the bond price $P_{t, T}$ and the real cumulative default probability $\operatorname{Pr}(t, T)$ in this jump-diffusion model are shown in the appendix.

\section{Calibration Method}

The key idea behind our calibration approach is that each model (with the associated choice of all of its parameters) that we use to calculate credit yield spreads should reflect the severity of default risk - both the expected default frequency (EDF) and the average loss rate given default-actually experienced by bondholders. So our 
calibration method should be designed around the availability of default experience data.

Data on default probabilities and loss rates provided by the rating agencies (such as Moody's and Standard and Poor's) are grouped by rating categories. To make use of such data, we focus our analysis on all companies with the same credit rating at a given point in time, rather than on any individual company. Specifically, we consider companies that have the following credit ratings by Moody's: Aaa, Aa, A, Baa, Ba, and B. Since we use data from both Moody's and Standard and Poor's, we make a reasonable assumption that the two rating systems have the following one-to-one mapping: $\mathrm{Aaa}=\mathrm{AAA}, \mathrm{Aa}=\mathrm{AA}, \mathrm{A}=\mathrm{A}, \mathrm{Baa}=\mathrm{BBB}, \mathrm{Ba}=\mathrm{BB}, \mathrm{B}=\mathrm{B}$.

We use Moody's as our source of data on historical default frequencies and loss rates given default (see Keenan, Shtogrin, and Sobehart (1999)). ${ }^{8}$ Since both the credit rating and the default recovery rate of a bond depend on the seniority of the bond, it is important that the historical default frequency and the average default loss rate against which we calibrate our models correspond to bonds with the same seniority. The historical default probability estimates reported by Moody's correspond to senior unsecured bonds. ${ }^{9}$ So for the default recovery rate, we should also use that of the senior unsecured bonds, which was reported to be $51.31 \%$. Altman and Kishore (1996) used a different methodology and arrived at similar numbers for the default recovery rate.

When we calibrate a structural model for a given credit rating, we imagine a representative firm which has a senior unsecured bond outstanding, and assume that the bond issued by our generic firm has the same probability of default as the historical probability of default for bonds of the same seniority and credit rating. The recovery rate given default for the bond is assumed to be the same as the historical default recovery rate for bonds of the same seniority and credit rating.

Table 1 contains, among other things, the historical cumulative default probabilities over various time horizons for bonds of each initial credit rating, and the average

\footnotetext{
${ }^{8}$ See Carey and Hrycay (2001) for a careful discussion of issues on using credit rating to predict the default probability.

${ }^{9}$ Of course, in arriving at such estimates, Moody's needs to use a procedure to "back out" from each subordinated and senior secured bond an implied senior rating. Such a procedure can create biases, which is why we should take caution when using the reported default probabilities. Later in the paper, we will do sensitivity analysis with our results by altering the estimates of historical default probabilities.
} 
recovery rate given default, both from Moody's.

It should be pointed out that our credit-rating-based calibration approach does not actually require that we know the criterion used by the rating agencies. All we need to assume is that bonds with different credit ratings represent bonds with different levels of credit risk and therefore different required credit spreads. Given that we consider only six broad credit rating groups, this assumption is likely to hold.

So far we have emphasized the unique aspect of our calibration approach; that is, we require that each model for each credit rating match the actual severity of default loss. The rest of our calibration approach, however, is very similar to standard applications of structural models employed by many previous studies, which we briefly outline below.

First, our models should also take into account balance sheet information for companies with different bond credit ratings. One important variable is the firm leverage ratio. Standard and Poor's (1999) provides the average leverage ratio for companies with bonds of a given credit rating. In our approach, we calibrate our model for each credit rating to this reported average leverage ratio, which is shown in column 2 of Table 1.

Secondly, we also calibrate our models to equity market data. Each structural model generates predictions of not only bond prices, but also equity prices. Since the equity market has higher liquidity and better data accuracy than the corporate bond market, it is useful for us to utilize data in the equity market to calibrate our models.

One important equity variable that our models should be calibrated against is the equity premium. This variable is important for our calibration approach because the predicted bond default probability (in the real world as opposed to the risk-neutral world) depends on the firm's asset risk premium. Although a levered firm's asset risk premium is not directly observable, it is closely related to the firm's equity premium. So calibrating to the equity premium allows us to accurately model the firm's asset risk premium. In contrast, standard applications of structural models seldom use the equity premium because of their focus on bond pricing, which can be carried out under the risk-neutral probability measure.

Since companies with different credit ratings may have different equity premia, we need to calibrate our model with different equity premia for companies of different credit ratings. Bhandari (1988) shows how cross-sectional equity returns are related to leverage ratios. Using Bhandari's estimates of regression coefficients, and noting 
that the average equity premium and leverage ratio for $\mathrm{S} \& \mathrm{P} 500$ companies are, respectively, roughly $6 \%$ and $35 \%$, we arrive at a set of estimates for the equity premium which varies with the company's credit rating. The results of such estimates are shown in column 3 of Table 1.

Table 1 also shows the historical average yield spreads over Treasury bonds of similar maturities by credit rating. Spreads on 10-year investment grade bonds are based on the Lehman bond index data from 1973-1993. This time period is intentionally chosen to be shorter by 5 years than the 1973-1998 time period for which Moody's reports 10 -year default frequencies, so that both the historical yield spreads and the historical default frequencies are likely to be recorded on the same sets of bonds. For 4-year investment grade bonds, the historical yield spreads were based on those for noncallable bonds from 1985-1995 from Duffee (1998). To be consistent with the 10-year investment grade bonds (which contain both callable and noncallable bonds), we have added back about $10 \mathrm{bp}$ of call-option spreads based on the work by Crabbe (1991). Historical junk bond yield spreads are harder to estimate. Here, we rely on estimates in Caouette, Altman, and Narayanan (1998) for both 4-year and 10-year maturities.

These estimates of historical corporate bond average yield spreads are, of course, not precise. But readers should not be overly concerned with this issue since our calibration approach does not rely on these yield spread estimates as input parametersthey only serve as references for comparison with our calculated credit yield spreads.

To summarize, for bonds of each credit rating, we need to calibrate structural models to match four target quantities: the initial leverage ratio, the equity premium, the cumulative default probability over a given future time horizon, and the recovery as a fraction of face value given default. Table 1 contains all such information.

Readers may notice that we choose not to require that our models match the observed equity volatility, a key variable that standard applications of structural models normally try to match. This choice, however, does not represent a difference between our approach with the standard calibration approach. Our approach only emphasizes the need to match historically observed default loss experience, but it does not at all rule out matching variables such as equity volatility.

Our choice to not match equity volatility for bonds of each credit rating is made for a few simple reasons. First, we do not have ready access to estimates of equity volatilities by company credit ratings. Secondly, as many studies since Shiller (1981) 
have shown, firms' equity return volatilities may be too high to be justified by the fluctuation of the firms' fundamental asset values. To the extent that the default risk of a bond is driven primarily by the potential deterioration of the firm's fundamental asset value, the observed volatility of the firm's equity return may not accurately represent the potential default loss of the firm's corporate bond. Given that we already require that our models match historical default probabilities, we do not deem it necessary for us to match equity volatility as well.

In the end, the choice to not match equity volatility does not have a significant impact on our quantitative results. Later in the paper, we will conduct sensitivity analysis which shows that our results would not have changed much had we calibrated our models to equity volatility.

We now turn to structural models and talk about how we choose our model parameters.

\section{Model Calibration}

To specify any structural model quantitatively, we need to choose the following set of parameters (or processes when the variable is stochastic): the initial firm value $V_{0}$ (as a multiple of the total face value of bonds outstanding), the interest rate $r$, the asset risk premium $\pi^{v}$, the asset payout rate $\delta$, the asset volatility $\sigma_{v}$, the jump process parameters in the case when the value process has a jump component, the default boundary $V^{*}$, and the default recovery rule.

Here is how we choose our model parameters. We choose $r$ according to its historical average (for the constant interest rate model) or according to a fitted interest rate model (for stochastic interest rate processes). We choose $\delta$ to be consistent with the historical average asset payout rate. For some models, $V^{*}$ is determined endogenously. For other models, we set $V^{*}$ to be roughly the average recovery amount for bonds plus any bankruptcy costs and costs due to the violation of absolute priority rule. Specific numerical choices of these parameters and processes, as well as parameters for the jump component of the asset value process, will be discussed in the next section when we present results.

Four important parameters, $V_{0}, \pi^{v}, \sigma_{v}$, and the default recovery rate, are still to be determined. For each model calibrated to each credit rating, we choose these four parameters such that the model matches the four target parameters: the initial lever- 
age ratio, the equity premium, the cumulative default probability, and the recovery rate given default. Again, models with jumps in the firm value process require special attention, which we will address later on.

In this calibration approach, we need to know formulas for bond prices and default probabilities. Such formulas for all models considered in this paper can be found in section 2 or the appendix.

Before we present results and discussions, we want to point out that in our calibration approach, as we average over historical time periods as well as over companies with bonds of similar credit ratings, we ignore the cyclicality and predictability of default rates. Ideally, one would like to calibrate our models for each time period separately so that the models are consistent with each time period's expected default probability. But given the limited historical data on defaults and given the noisy nature of default rates over any short period of time, it is very difficult to have any precise estimate of the expected default probability if we limit ourselves to a short time period.

\section{Results and Discussions}

In this section, we present and discuss our calibration results from various structural models. We organize our presentations and discussions by the economic considerations proposed by these models, rather than by the models themselves.

We choose the Longstaff-Schwartz model to present our base case around which we introduce different economic considerations. The analytic flexibility of, and the ease of extensions from, the LS model allow us to analyze the effects of stochastic interest rates, mean-reverting leverage ratios, and time-varying and predictable equity risk premia on our calibration results.

\subsection{The Base Case}

Our "base case" uses the LS model with a constant interest rate. Stochastic interest rates will be considered later. The base case also requires a full set of parameters as inputs. We now specify the choice of the parameters.

First, we need to choose target parameters for each credit rating. For the base case, the target initial leverage ratio (defined as the ratio of the market value of debt to the market value of firm asset), the target expected equity premium, the target 
cumulative default probability, and the target default recovery rate are all chosen according to Table 1 .

Second, we need to choose parameters for the credit risk models. Four model parameters - the initial firm value $V_{0}$, the asset risk premium $\pi^{v}$, the asset volatility $\sigma_{v}$, and the default recovery rate $w$-will be determined by calibration to match the above target parameters. This leaves three parameters to be determined: the asset payout rate, the interest rate, and the default boundary.

For the asset payout rate, we use $\delta=6 \%$ for all firms. In principle, this payout rate should represent the average total net annual payments to holders of all of the firm's securities (which includes all coupon, principal, and dividend payments, plus proceeds from all security issuances, minus all share repurchases) as a fraction of the firm's asset value. As a rough estimate, we can take the weighted averages between the average dividend yields (which is close to $4 \%$ according to Ibbotson Associates (2002)) and the average historical coupon rate (which is close to 9\% during 19731998, the time period for which we calibrate our models), with weights given by the average leverage ratio of all firms (which is close to $35 \%$ for S\&P 500 firms). This rough estimate gives a payout rate that is close to $6 \%$.

We do not assume different asset payout rates for firms with different credit ratings. Firms with junk bonds may have more debt and higher coupon rates than firms with investment-grade bonds, but they are likely to pay much less dividends. In any case, we will show later that our calibration results are not sensitive to this choice.

For the interest rate, we will choose a continuously compounded constant rate of $r=8 \%$. This is close to the historical average Treasury rates during 1973-1998.

The last parameter we need to choose is the boundary of default. In the original LS model, default is assumed to occur when the firm value falls to the bond face value. This assumption, however, may not be very reasonable given that bondholders on average recover only about $51 \%$ of the face value given default; after all, it is difficult to believe that $49 \%$ of the firm value is lost due to bankruptcy costs or the violation of absolute priority rule. So for our base case, we assume a lower default boundary $V^{*}$ at $60 \%$ of the bond face value. ${ }^{10}$ Upon default, bondholders recover

\footnotetext{
${ }^{10}$ In order to make the assumption that the default boundary in the LS model can be below the bond face value $F$, we need to reinterpret the model and let $F$ denote the total amount of liabilities. If the firm has only one corporate bond maturing in 10 years, then the default boundary has to be close to the face value near bond maturity.
} 
about $51 \%$ of the face value, which is about $85 \%$ of the firm value at default. The $15 \%$ loss rate (for firm's asset) is consistent with previous findings that bankruptcy costs are about 10-20\% of firm value (see, for example, Andrade and Kaplan (1998)) and that the violation of absolute priority rule represents only a small fraction of the firm's value. Later on in the paper, we will conduct sensitivity analysis to show that the calculated credit yield spreads in our calibration approach are not very sensitive to this choice of the default boundary.

Third, we need to choose the maturities and coupon rates for corporate bonds. To study bonds with a range of maturities, we consider bonds with both 4 -year and 10-year maturities. Occasionally, we also consider 1-year maturity bonds to highlight our results for short-term bonds.

We choose the coupon rate to be $8.162 \%$, which is the par coupon rate for riskfree bonds with semi-annual coupon payments when the continuously compounded interest rate is $8 \%$. One obvious alternative is to choose a different coupon rate for bonds of each credit rating so that the corporate bond is initially priced at par. We made our choice so that the LS default recovery rule matches the way default recovery data is recorded by Moody's. While Moody's reports default recovery rate as a fraction of the face value received on the day of default, the LS model assumes that upon default, each holder of a coupon bond is assumed to continue to receive with certainty an exogenously specified fraction of all future payments according to the original time schedule. When we choose the coupon rate to be the par coupon rate for an otherwise riskfree bond, the bondholder in the LS model effectively receives the specified fraction of the face value, in terms of market value, on the day of default. This makes it possible for us to calibrate the LS model to Moody's default data. To correct for the fact that this choice of coupon rate may underestimate the coupon rate for junk bonds, we calculate all leverage ratios by using the market value, rather than the face value, of bonds.

With the above parameter choices and coupon bond terms, we can now calibrate the 1-factor LS model for our base case. The calibration results, as well as the calculated credit yield spreads from such calibrated models, are shown in Table 2. Figure 2 also illustrates some of the main results for 10-year bonds. In Table 2, we have three panels, corresponding to 10-year, 4-year, and 1-year maturities. For each maturity in a given panel, and for a given credit rating corresponding to each row, the table shows the target initial leverage ratio (column 2), the target equity premium 
(column 3), the target cumulative default probability up until maturity (column 4), the implied asset volatility (column 5) and the asset risk premium (column 6) that allow the calibrated model to match all targets, the calculated credit yield spread (column 7) from the calibrated model, the historical average yield spread (column 8), and our calculated credit yield spread as a percentage of the historical average yield spread. For 1-year maturity bonds, we cannot find estimates of corporate-Treasury yield spreads as corporate bonds are rarely traded close to their maturities.

A few conclusions can be reached based on our base case results. First, for investment grade bonds (those with a credit rating not lower than Baa) of all maturities, credit risk accounts for only a small fraction of the observed corporate-Treasury yield spreads, and the fraction is typically smaller than $20 \%$ except for 10-year Baa-rated bonds.

Second, credit risk accounts for a much larger fraction of the observed corporateTreasury yield spreads for junk bonds than for investment grade bonds. This result is reasonable because, for junk bonds, the level of credit risk is much higher while factors such as illiquidity are not proportionally more severe; in fact, some junk bonds may be even more liquid than investment grade bonds because of higher trading volumes.

Third, among investment grade bonds, the shorter the maturity, the smaller the fraction of the observed yield spreads can be explained by credit risk. This is reasonable because mean reversion of credit quality over time could lead to higher credit risk for investment grade bonds with longer maturities, and factors such as illiquidity have a larger impact on yield spreads of bonds with shorter maturities simply because trading costs have to be amortized over a shorter holding horizon.

For the short end of the maturity spectrum (with about one year to maturity), according to the base case calculation, credit risk accounts for only a tiny portion of the observed yield spreads for investment grade bonds. In some sense, this observation is not new; many previous studies have shown that structural models with a diffusion-type firm value process always generate a very small credit yield spread for short maturities. Most researchers, believing that credit risk should account for more than just a few basis points of the short-term corporate yield spreads, view this as a failure of diffusion-type structural models. Proposed theoretical improvements include incomplete accounting information (Duffie and Lando (2001)) and firm value processes with jumps (Zhou (2001) and Delianedis and Geske (2001)).

But our result here suggests that incorporating jump risk may still not be enough 
for credit risk to explain short-term corporate spreads; credit risk may indeed only account for a very small fraction of the yield spreads for short-term investment grade bonds simply because such bonds rarely default within a short time interval. Structural models that obtain high credit yield spreads by introducing jumps into the firm value process may have done so by predicting counterfactually high default probabilities over short time intervals. Later in the paper, we will provide some evidence of this alternative view by studying a structural model with a jump diffusion firm value process.

For investment grade bonds with medium to long maturities, there is much less consensus on how much of the observed yield spreads can be explained by credit risk. So in the remainder of the paper, we mostly focus on 4-year and 10-year corporate bonds.

For reasons discussed previously, we do not calibrate our models to match equity volatility. But the implied asset volatilities generated by our calibration for the base case are broadly consistent with empirically estimated levels of total risk of individual firms. ${ }^{11}$

One important question is whether our results are mostly driven by the fact the Treasury yields may not be "clean" riskfree interest rates. A widely held belief is that the term swap rates may be better riskfree rates. Although one can argue that swap rates themselves contain some credit spreads, to make sure that our results are not entirely driven by our choice of Treasury yields as riskfree reference rates for corporate spreads, we also did our calculations with the corporate-Treasury yield spreads replaced by the spreads between corporate bonds and swap rates of comparable maturities. We find that our main qualitative conclusions remain the same for corporate bonds below the Aaa rating. For example, for 10-year maturities, the average swap spreads during 1988-1995 is 52 basis points. Using the swap rates as riskfree rates, according to our base case calculation, credit risk accounts for, respectively, 39\%, $34 \%, 41 \%, 73 \%$, and $93 \%$ of the spreads of corporate yields over swap rates for bonds rated $\mathrm{Aa}, \mathrm{A}, \mathrm{Baa}, \mathrm{Ba}$, and $\mathrm{B}$.

The base case is our starting point of analysis. It is important to know whether

\footnotetext{
${ }^{11}$ Goyal and Santa-Clara (2002), for example, find that average equity volatility over the last few decades is about $55 \%$. This may be large compared to our implied asset volatility numbers, even after adjusting for the leverage effect. One reason is that companies with investment-grade bonds may have lower asset and equity volatilities. Another reason is probably due to the excess volatility in the equity market (see, for example, Shiller (1981)).
} 
models that introduce other economic considerations would change our results, and whether our results are sensitive to the choice of parameters. We take up these issues next.

Specifically, we will ask whether our results will be significantly different when we consider that: (i) interest rates may be stochastic (the Longstaff-Schwartz twofactor model); (ii) the default boundary should be endogenously determined as firms issue equity to avoid default (Leland-Toft); (iii) firms may default strategically to extract concessions from bondholders (Anderson-Sundaresan, Anderson-SundaresanTyphon, and Mella-Barral and Perraudin); (iv) firms adjust their leverage ratios, making them mean-reverting (Collin-Dufresne and Goldstein). We will show that all of these models generate very similar results on credit yield spreads under our calibration approach.

In order to gain a better understanding of credit risk premia, we next study models that incorporate higher risk premia for states of the economy with a higher default likelihood. We introduce two additional models to explore this issue: one with a counter-cyclical market risk premium, and one with a jump-diffusion firm value process.

In addition, we also conduct sensitivity analysis with different parameter choices.

As we will show below, the quantitative results obtained in our base case remain very robust when we consider the above economic assumptions about credit risk valuation, as long as we use empirically reasonable model parameters.

As we go through various models which include many existing models, please bear in mind that we are merely focusing on the quantitative question of how much of the observed corporate yield spread is due to credit risk. Each of these models is a nice extension of the Merton (1974) credit risk model within the structural approach that studies how certain realistic economic considerations would affect credit risk valuation. We are simply applying these models - together with the idea that each of them should match actual historical default loss experience- to estimate credit yield spreads for corporate bonds. Even though we may reach different quantitative conclusions than the original authors about the level of credit risk, we do not in any way question the validity of these models.

\subsection{Stochastic Interest Rates}

One realistic consideration ignored in the base case is that the interest rate is 
stochastic. To study the effect of stochastic interest rates on our calculations, we calibrate the original two-factor LS model with a stochastic interest rate that is given by the Vasicek (1977) model (see (5) and (6)). The parameters for the interest rate process are chosen as: ${ }^{12}$

$$
\kappa_{r}=\bar{\kappa}_{r}=0.226 ; \quad \theta=11.3 \% ; \quad \bar{\theta}=6.2 \% ; \quad \sigma_{r}=4.68 \%
$$

The correlation coefficient between the interest rate process and the firm value process is assumed to be $\rho_{r v}=-0.25$, following LS. The initial interest rate at time zero is set to be $8 \%$.

Table 3 presents the results of this calculation for 4 -year and 10-year bonds. The results show that all of our conclusions reached in the base case remain true. In particular, the calculated credit yield spreads for all credit ratings under the assumption of a stochastic interest rate are even smaller than those in the base case.

The reason that stochastic interest rates have a negative impact on our calculated credit spread is as follows. First, observe that the long-term mean interest rate in the risk neutral measure is always higher than in the real probability measure. In our example above, $\theta=11.3 \%>\bar{\theta}=6.2 \%$. This is not unique to the Vasicek model any term structure model that tries to explain the positive premium for holding longterm bonds inevitably assumes that the long-term mean for the interest rate process under the risk-neutral measure is higher than under the real probability measure so that long-term bond prices are "fair" relative to short-term bonds.

This observation allows us to understand why stochastic interest rates reduce the credit spread calculated in our calibration approach. Note that, holding other model parameters constant, a higher interest rate leads to a lower default probability, as the firm value has a higher drift rate. If the interest rate is constant, then the interest rates under both the real and risk-neutral measures are the same constant. But a stochastic interest rate (appropriately calibrated to term structure data) generates a higher long-term mean under the risk-neutral measure than under the real measure, and this drives the risk-neutral default probability lower relative to the real default probability. In our approach, since our model is always calibrated to generate the same empirically observed real default probability, stochastic interest rates drive down the risk neutral probability of default as well as the calculated credit spread.

\footnotetext{
${ }^{12}$ These parameters were obtained from Qiang Dai.
} 
At a more basic level, medium- and long-term corporate bond yield spreads are measured against Treasury bonds of similar maturities, but equity premia tend to be measured against short-term Treasury yields. When we use a stochastic interest rate process that matches the fact that long term Treasury bonds generate higher average returns than short-term Treasury securities, the effective equity - and thus assetrisk premia measured over medium- and long-term Treasury securities are smaller, which results in lower credit risk premia for medium- and long-term corporate bonds as well.

\subsection{Endogenous Default Boundary Based On Zero Equity Value}

One issue with the LS model is that the default boundary is specified exogenously. Ideally, we would like to know whether an endogenously derived default boundary, by imposing more structure on the model, may have a large quantitative effect on our calculated credit spread. Unfortunately, not many models of this type are analytically tractable for the purpose of calibration. Two groups of structural models have endogenously derived default boundaries under some restrictive simplifying assumptions. The first group, by Black-Cox (1976), Leland (1994), and Leland-Toft (1996), assumes that firms delay default as much as possible by issuing equity to service debt coupon payments, and default occurs when the equity value is zero. We consider this group of models here. The second group incorporates strategic default, which we will take up next.

The calibration approach for the Leland-Toft (LT) model and for all parameter choices are the same as in the base case, except for differences in bond maturity and in modeling. Results are shown in Table 4. We only show results for 10-year bonds here because the version of LT model we calibrate here assumes infinite maturity.

At first glance, the LT model seems to generate higher credit spreads for investmentgrade bonds than the LS model did in our base case. This, however, is due to the fact that the LT model considered here has a perpetual bond, which, for investment grades, should have a higher credit spread than a 10-year bond. The only other difference between the LT and the LS models, given that we have calibrated the two models in the same way, is in their default boundaries - the endogenously determined default boundary in the LT model in general differs from the exogenously specified default boundary in the LS model. This, however, cannot explain the difference in credit spreads as our calculated credit yield spreads are not sensitive to the choice of 
default boundaries.

To check that the higher investment-grade credit spread calculated in the LT model is indeed due to the infinite maturity of the perpetual bonds in LT, we take the exact same asset risk premium, default boundary, and asset volatility which the LT model generated in Table 4 for Aaa- and Aa-rated bonds, and then plug these parameters into the Longstaff-Schwartz model to calculate the credit yield spreads of a 10-year bond. Such calculation shows a spread of only 8.9 bp and $12.4 \mathrm{bp}$, respectively, for Aaa- and Aa-rated 10-year bonds, which are much lower than those given by the LT model. Note that this is a precise comparison as both models use the same underlying firm value process and our calibration ensured that all other parameters are identical.

One nice feature of the LT model is, as the calibration results show, that it does endogenously generate default boundaries that are much lower than the bond face value. This is reasonably consistent with the fact that historical average default recovery rate is only about $51 \%$ of the bond face value even though bankruptcy costs should be smaller than 20\%. Occasionally, however, the default boundary can be even lower than $51 \%$ of the face value, making it impossible for the model to match the $51 \%$ average recovery rate. In such cases, we cap the recovery to be whatever the firm value is at default.

\subsection{Strategic Default}

Another set of models of credit risk with endogenous default boundaries are given by Anderson-Sundaresan (1996), Anderson-Sundaresan-Tychon (1996), and MellaBarral and Perraudin (1997) (collectively AST-MBP). While the LT model assumes that firms try to delay default as much as they can by issuing equity to service debt if necessary, the AST-MBP approach assumes that firms default strategically to extract concessions from bondholders whenever possible.

One of the important conclusions from the strategic default approach in AST-MBP is that firms are more likely to default than suggested by the traditional approach in Merton (1974) and the model in Longstaff-Schwartz (1996). As a result, AST-MBP showed that their approach does a better job at explaining the empirically observed high corporate-Treasury yield spreads for investment-grade bonds.

Our calibration calculation, however, arrives at a different conclusion. Table 5 
shows the results of our calibration. ${ }^{13}$ Again, we only show results for 10 -year bonds because the AST-MBP model we calibrated here assumes infinite maturity. As in the LT model, at first glance, the AST-MBP model seems to generate much higher credit spreads for investment-grade bonds than the LS model did in our base case. This, however, is again due to the fact that the AST-MBP model considered here has a perpetual bond, which, for investment grades, should have a higher credit spread than a 10-year bond. To check that this is indeed the case, we take the exact same asset risk premium, default boundary, and asset volatility which the AST-MBP model generated in Table 6 for Aaa-rated bond, and then plug these parameters into the Longstaff-Schwartz model to calculate the credit yield spread of a 10-year bond. Such calculation shows a spread of only $12.8 \mathrm{bp}$, which is much lower than given by the AST-MBP model. Again, note that this is a precise comparison as both models use the same underlying firm value process and our calibration ensured that all other parameters are identical.

Our result here suggests that it might not be reasonable to conclude that strategic default models can explain all of the observed corporate-Treasury yield spreads through credit risk. Strategic defaults can indeed make it more likely that equity holders would renegotiate with bondholders - out of bankruptcy courts-to gain concessions, but since any such renegotiation is treated as "default" by rating agencies (such as Moody's), such models tend to predict higher default probabilities than actually observed. So it remains very difficult for strategic default models to explain corporate yield spreads, if we require that such models be consistent with historical default experience data.

Comparing the AST-MBP model with the LT model, we note that endogenous defaults in strategic models tend to occur at firm values that are above the face value of the debt. This may make it difficult to understand why bondholders receive, on average, only roughly $51 \%$ of the face value given default while bankruptcy costs are smaller than $20 \%$ of the firm asset value. So it is probably more reasonable to take the view that strategic default models represent a subset of firms for which strategic

\footnotetext{
${ }^{13}$ We do not show results for junk bonds because we cannot find a set of parameters that satisfy our calibration requirements.
} 
default is a reasonable approximation of reality.

\subsection{Firms with Mean-Reverting Leverage Ratio}

Collin-Dufresne and Goldstein (2001) (CDG) proposed a model that incorporates the idea that firms may adjust their outstanding debt levels in response to changes in firm value, which makes the stochastic leverage ratio mean-reverting. They argue that, under such considerations, the calculated credit yield spreads on long-term investment grade bonds are comparable to those observed in corporate bond data, since these firms tend to increase their leverage ratio over time by increasing debt issuance. Ericsson and Reneby (2001) reached similar conclusions under similar assumptions.

We apply our calibration approach to the CDG model. The results are shown in Table 6. For parameters in the CDG model (see (12) and (13)), we choose the meanreversion coefficient $\kappa_{l}=0.2$, and the long-term average leverage ratio $\bar{\ell}=38 \%$. These numbers are similar to those chosen in CDG, and also comparable to those found in empirical studies (see Fama and French (2002a)).

The results in Table 6 show that, the calculated credit yield spreads in the CDG model under our calibration approach are very similar to the results in our base case. The higher credit yield spread generated in the original CDG approach is due to the

higher default probability driven by the assumption that firms with high credit quality may increase their debt outstanding, rather than due to a higher credit risk premium. Once we force the model to match the empirically observed default frequency, we are still left with the conclusion that, according to the CDG model, credit risk accounts for only a small portion of the observed corporate-Treasury yield spreads on long-term investment grade bonds.

\subsection{Discussions and Further Directions}

The above structural models of credit risk have generated very similar credit yield spreads. Despite the fact that these models made very different economic assumptions, their predicted credit risk premia do not differ much once each of them is calibrated to match the same historical default loss experience. So it might be useful for us to ask whether going beyond the common features of these models can allow us to capture some key economic reasons for why credit risk premia should be very high. Indeed, by deviating from two common assumptions in the above models - a constant 
asset risk premium ${ }^{14}$ and a one-factor diffusion firm value process - we can capture some important considerations that could lead to very high credit risk premia.

Intuitively, one potentially important cause of high credit risk premia is the existence of certain states which are associated with both high default probabilities and high market risk premia. To make this intuition precise, we consider two mechanisms through which the existence of such states can lead to high credit risk premia.

The first mechanism is that, at some of these states (with high default risk), the market risk premia are abnormally high. This results in time variation in market risk premia which can be predicted with the identifying variables of such states. An example of such states is the bottoms of business cycles. Many researchers have shown that the aggregate market risk premium is counter-cyclical (see, for example, Campbell, Lo, and MacKinlay (1997)), and that business cycle variables such as the market dividend yield can help predict the aggregate equity premium. Given that the level of credit risk is also counter-cyclical, the market risk premium tends to be high when the level of credit risk is also high. So a model that captures such time variation might be able to predict a high credit risk premium. We will consider such a model below.

The second mechanism is that the stochastic discount factors (or investors' marginal utilities) for certain future states (with high default risk) can be "abnormally high," in a sense to be made precise soon. The structural models studied so far-all with one-factor diffusion firm asset value processes - have certainly allowed for the existence of future states with both high default risks and high stochastic discount factors; they are future states with severe negative shocks on firms' asset values. Our second mechanism, however, assumes that there exist certain future states with high default risks for which the stochastic discount factors are much higher than those suggested by models with one-factor diffusion asset value processes.

A simple example of such states is large downward jumps in asset values, which are associated with high default risks. The market may view jumps in asset values as particularly risky and require high stochastic discount factors (or high marginal utilities) for such jump states. Considerations of such special states can potentially

\footnotetext{
${ }^{14}$ Strictly speaking, however, this is an assumption that we made so far. The above models mostly focused on the pricing of corporate bonds under the risk-neutral probability measure. Although these models - at least in their original versions - typically make the explicit assumption of a constant asset risk premium, their validity extends to time-varying risk premia as well.
} 
lead to very high credit risk premia. To capture such effects, we implement a jumpdiffusion structural credit risk model below.

Note that the second mechanism is distinctly different from the first mechanism. In fact, in our model with jumps in asset values, the jumps are unpredictable and there is no time variation in market risk premia.

Another class of credit risk models that may be worth exploring are ones in which the firm value process has stochastic volatilities. Stochastic asset volatilities may lead to high credit risk premia through both of the above mechanisms. If states with high asset volatilities have high market risk premia, then the first mechanism can work. If there exist future regimes (or states) with high volatilities that have very high stochastic discount factors (because investors are particularly concerned about such states), then the second mechanism can work. But because of lack of tractability of credit risk models with stochastic volatilities, particularly of default probability calculation for coupon bonds, we leave a full study of this case for future research. Fortunately, however, the effects of stochastic asset volatilities through both mechanisms can be partially captured by our representative models for both mechanisms. The effects of stochastic asset volatilities through the first mechanism can be partially captured by a time-varying market risk premium with the stochastic volatility as the predicting variable, and the effects through the second mechanism can be partially captured by our jump-diffusion model, since jumps, after all, can be thought of as very short-lived regimes with extremely high volatilities.

Each of the above considerations can potentially explain all of the observed corporateTreasury yield spread through credit risk if we make certain parameter assumptions. The key, however, is whether they can do so under empirically reasonable parameter choices.

\subsection{A Counter-Cyclical Risk Premium}

We use a model with a counter-cyclical market risk premium to capture our first mechanism. A counter-cyclical risk premium should, at least qualitatively, lead to a higher credit yield spread under our calibration approach. A firm's asset return is typically positively correlated with the aggregate market return. This implies that, if a firm's asset return experiences a negative shock, then it is more likely that the subsequent risk premium is higher (for both the aggregate market and individual firms' asset returns). This results in a lower real default probability with a counter- 
cyclical asset risk premium than with a constant asset risk premium, holding the average asset risk premium the same. But since bond prices will not be affected by changes in the asset risk premium due to risk-neutral pricing, the net effect of a counter-cyclical asset risk premium is that corporate bonds can potentially have low prices (and high yields) while experiencing low default probabilities.

To investigate whether this effect can make a significant quantitative difference in our calibration calculation under empirically reasonable assumptions, we apply our approach to the model with a time-varying asset risk premium introduced in section 2 .

We first need to assign numerical values for parameters $\kappa_{\pi}, \bar{\pi}^{v}$, and $\sigma_{\pi}$ for the asset risk premium process in (15). We start with the following aggregate equity market risk premium process as calibrated in Campbell and Viceira (1999) for annual S\&P 500 data from 1890 to 1993:

$$
d \pi_{t}^{M}=\kappa_{M}\left(\bar{\pi}^{M}-\pi_{t}^{M}\right) d t+\sigma_{M} d W_{t}^{\pi^{M}},
$$

where

$$
\kappa_{M}=0.202 ; \quad \bar{\pi}^{M}=4.165 \% ; \quad \sigma_{M}=3.10 \% .
$$

The correlation between the market risk premium process with the market return process is $\rho_{\pi M}=-0.701$. To come up with a model for our individual firm asset risk premium, we combine the Campbell-Viceira calibration with the CAPM model,

$$
R_{i, t}=r_{f}+\beta_{i}\left(R_{M, t}-r_{f}\right)+\epsilon_{i, t},
$$

where $\epsilon_{i, t}$ represents firm $i$ 's idiosyncratic risk that is uncorrelated with all other variables.

The final parameter choices for the individual firm asset risk premium process are

$$
\kappa_{\pi}=0.202 ; \quad \bar{\pi}^{v}=4.165 \% ; \quad \sigma_{\pi}=3.10 \%
$$

where we have assumed that the $\beta$ for a typical firm's asset is one in arriving at the estimate for $\bar{\pi}^{v}$. The correlation between a firm's asset risk premium and its asset return process is given by

$$
\rho_{\pi V}=\rho_{\pi M} \times \rho_{v M} \approx-0.701 \times 0.5=-0.351
$$

where we have used the fact that a typical firm's asset return correlation with the market return is about 0.5 . 
With these choices, the results of our calibration calculation are shown in Table 7. As expected, the predictability of the equity risk premium does produce a higher credit yield spread, but the quantitative effect is limited - credit risk still only accounts for a small fraction of the observed yield spread for investment-grade bonds, according to the model.

Of course, the model here can generate a much higher credit yield spread than that shown in Table 7 if we assume a much stronger predictable variation in the market risk premium. But given issues about statistical significance even for the documented predictability of the aggregate market risk premium (see, for example, Campbell and Yogo (2002) for a recent study), the high level of predictable variation in the risk premium necessary for this to be a potential explanation of the corporate-Treasury yield spread is not supported by existing empirical evidence.

We should also consider the possibility that individual firm asset returns may be time-varying and predictable, and that such time variation in these market risk premia could generate a higher average credit risk premium, even though time variation in the aggregate market risk premium is not strong enough. For this view to be valid, however, we need empirical evidence that individual firms with high default risk have high asset risk premia. But so far, there is not enough empirical evidence to support this view. On the contrary, Dichev (1998) showed that equities of firms with high bankruptcy risk actually earn significantly lower returns than average.

\subsection{Effects of Risky Jumps in the Firm Value Process}

To capture the second mechanism discussed in section 4.7 , we study a new structural credit risk model with a jump-diffusion asset value process. This model, introduced in section 2, allows for analytically tractable calculations for both prices and cumulative default probabilities of coupon bonds. We use this model to understand the effects on the credit risk premium of high default risk states with high equilibrium stochastic discount factors.

We calibrate the jump-diffusion model as follows. First, we need to calibrate the jump process for firm asset value returns under the real probability measure. Given that no study has estimated the jump components for asset returns of individual firms with bonds of a given credit rating, we rely on estimation results from S\&P 500 index data, and choose the following parameters which are roughly consistent with 
the recent study by Anderson, Benzoni, and Lund (2001):

$$
\lambda=3 ; \quad p_{u}=p_{d}=\frac{1}{2} ; \quad \eta_{u}=\eta_{d}=30 .
$$

Individual firms' asset return processes may not be described by this set of parameters which are based on S\&P 500 data. But fortunately, our calculation showsas intuition would suggest - that idiosyncratic jumps that (according to traditional theory) do not require a risk premium would not affect our calculated credit risk premium. $^{15}$ So it is reasonable for us to only focus on those individual firm asset value jumps that are part of systematic jumps in the market, which can be represented by S\&P 500 jumps.

We also need to calibrate the firm value process under the risk-neutral probability measure. For the real to risk-neutral probability measure transformation, the diffusion part can be treated as usual, but the jump component needs special attention. Given the double-exponential jump-diffusion firm value process, the market for state contingent claims on the firm asset value is not dynamically complete, leading to infinitely many possible jump processes under the risk-neutral measure. So we need to go beyond purely arbitrage-based methods, and make equilibrium-based assumptions.

Guided by equilibrium considerations and restricted by analytic tractability, we assume the following simple one-parameter form of the transformation between the real and risk-neutral measure for the jump process:

$$
\begin{aligned}
\lambda^{Q} & =\lambda \mathbf{E}\left(Z_{i}^{-\gamma}\right) \\
f^{Q}(z) & =\frac{z^{-\gamma}}{\mathbf{E}\left(Z_{i}^{-\gamma}\right)} f(z)
\end{aligned}
$$

where $f^{Q}(\cdot)$ and where $f(\cdot)$ denote, respectively, the density function of the jump size distribution under the risk-neutral and real measures. This transformation is partly motivated by analytic tractability; it is one of the few transformations that would allow the risk-neutral jump process to also have the double-exponential distribution (see Kou (2002)), with the following parameters:

$$
\eta_{u}^{Q}=\eta_{u}+\gamma
$$

\footnotetext{
${ }^{15}$ Of course, idiosyncratic jumps certainly affect real default probabilities, but recall that our calibration approach forces the model (with both diffusion and jump risk) to match the historical default frequency anyway, so that we are focusing on the effect of jumps on the credit risk premium.
} 


$$
\begin{aligned}
\eta_{d}^{Q} & =\eta_{d}-\gamma \\
p_{u}^{Q} & =\frac{\frac{p_{u} \eta_{u}}{\eta_{u}+\gamma}}{\frac{p_{u} \eta_{u}}{\eta_{u}+\gamma}+\frac{p_{d} \eta_{d}}{\eta_{d}-\gamma}}
\end{aligned}
$$

In addition, this transformation also has an appealing equilibrium interpretation. It is supported by a Lucas-type equilibrium in which the representative agent with a constant relative risk aversion of $\gamma$ holds the asset in equilibrium and consumes a constant fraction of his holdings each time period (see Kou (2002)). As a result, the marginal utility for downward jumps are higher than that for upward jumps.

The calibration of the transformation parameter $\gamma$ is done by assigning an empirically reasonable number to the jump risk premium, which is given by $\lambda \xi-\lambda^{Q} \xi^{Q}$. In order to dramatize the potential effects of jumps on the credit risk premium, we choose our transformation parameter $\gamma$ under the assumption that all of the firm's asset risk premium is due to its systematic jump risk. This could help strengthen our conclusion in the event that we find small credit risk premia and small credit risk spreads.

The rest of our calibration proceeds just as in the base case. The results are shown in Table 8. Our results show that incorporating jumps does not significantly change our base case conclusion. Credit risk still accounts for a small fraction of observed yield spreads for investment grade bonds of all maturities, but a much larger fraction for junk bonds.

Interestingly, credit yield spreads for investment grade bonds with very short maturities (such as 1 year) continue to be very small. Even with jump risk explicitly considered, structural models still show that only a very small portion of the observed corporate-Treasury yield spreads for short-term investment grade bonds is due to credit risk. This result casts doubt on the view that jump risk may allow structural models to explain the observed short-term high quality corporate bond yield spreads. Jumps in asset values may make it more likely for such bonds to default, but given the very small frequency of default over a short time interval for bonds of high credit quality, credit risk due to asset value jumps still cannot explain the observed yield spreads for such bonds.

As we emphasized before, some structural models of credit risk can, at least in theory, explain all of the observed corporate-Treasury yield spreads under certain parameter choices, even for investment grade bonds. The key is whether such parameter choices can be supported by empirical evidence. The jump-diffusion model here 
provides an example of such models. We will now show that this model can indeed explain all of the observed corporate yield spreads under certain parameter choices, but the required parameter choices seem rather extreme.

We present results for our jump-diffusion model under one such extreme set of parameter choices in Table 9, which indeed explain roughly all of the observed corporate yield spreads. The parameters chosen are

$$
\lambda=0.1 ; \quad p_{u}=p_{d}=\frac{1}{2} ; \quad \eta_{u}=\eta_{d}=5
$$

This set of parameters, however, makes a drastic assumption about the market risk premium. Specifically, it assumes that all of the observed aggregate market equity risk premium is due to those rare events during which the values of assets - not equitiesof all firms would drop by an average of $20 \%$, and that these rare events occur with an average frequency of once every 20 years (given that the jump intensity is once per 10 years and that jumps go up and down with equal probabilities). Many would agree that such a view may be extreme and might not be supported by empirical evidence.

It should be pointed out, however, that we have not considered all of the modeling possibilities that could generate high credit risk premia by deviating from one-factor diffusion firm asset value processes. These possibilities include multi-factor models for firm value processes, such as models with stochastic volatilities (see section 4.7 for a discussion on such models), as well as other transformations between the real and risk-neutral probability measures. It would be interesting to extend our approach to more sophisticated models in future research.

\subsection{Sensitivity Analysis of the Parameter Choices}

We now consider whether our conclusions are sensitive to the choices of our parameters. We start from our base case, and then change various parameter choices. To be conservative, we give more considerations to parameter choices that would lead to a higher calculated credit yield spread.

\section{Equity premium}

In our calibration approach, a higher equity premium, which implies a higher asset risk premium, should lead to a higher credit risk premium and a higher credit yield spread. 
One way to make sure that our results are not overly sensitive to our choice of the equity premium is to look at the effect of a higher equity premium. We start from the base case, and then add $2 \%$ to the equity premium for firms of each credit rating. Given that some researchers believe that the true equity premium may be smaller than $6 \%$ (see Fama and French (2002b)), and that the realized equity premium during $1973-1998$ is also less than $7 \%$ for firms with average leverage ratios ${ }^{16}$ this choice of a higher equity premium is conservative enough.

Results in Table 10 show that the calculated credit yield spread is indeed rather sensitive to the equity premium, but the total quantitative effect is still small.

\section{Default boundaries}

Throughout the paper, we have assumed that a firm defaults when its asset value hits $60 \%$ of the total face value of bonds outstanding. This assumption is made to be consistent with the facts that bankruptcy costs are roughly $15 \%$ of asset value and (senior unsecured) bonds recover on average about $51 \%$ of their face amount.

To make sure that our results are not overly reliant on this assumption, we do sensitivity analysis by considering different default boundaries. In Table 11, we focus on 10-year bonds and compare our base case (Panel B) with the case in which the default boundary is taken to be $100 \%$ of the total face value of firm's outstanding bonds (Panel A). The results show that our calculated credit yield spreads are not sensitive to the choice of default boundaries. Results for other maturities are also similar.

\section{Average initial leverage ratio for each credit rating}

It is possible that the average leverage ratios of bonds with different credit ratings as given in Standard and Poor's (1999) may not be precise. In Table 12, we deviate from our base case by assuming different initial leverage ratios for each credit rating. Specifically, for each credit rating, we choose a lower (or higher) initial leverage ratio by using the average of the initial leverage ratio for the given credit rating and that for the credit rating immediately above (or below) the given credit rating. The results for the lower and higher initial leverage ratios are shown, respectively, in Panels A and B. Both panels show that our calculated credit yield spreads are not sensitive to

\footnotetext{
${ }^{16}$ One may even argue that it is better to use the realized equity premium to calibrate our model since we use realized default probabilities over this time period.
} 
the choices of initial leverage ratios.

\section{Average asset payout ratio $\delta$}

We chose the asset payout ratio to be $\delta=6 \%$ in our base case. To make sure that our results are not sensitive to this choice, we looked at two other choices: $0 \%$ and 8\%. Results in Table 13 show that the calculated credit spreads are not sensitive to the choice of this parameter as well.

\section{Equity volatility}

As discussed previously, we do not calibrate our model to match observed equity volatility. Although this does not represent a difference between our approach and traditional calculation approaches, we would like to make sure that our results are not sensitive to this calibration choice.

Our calibration can be easily modified to allow for matching observed equity volatility as well. Doing so, however, requires us to relax a degree of freedom that we have already tied down. Among the parameter choices we made, such as the default boundary, the initial leverage ratio, and the asset payout ratio, we can change one, two, or all of them such that equity volatility is also matched. But given that our sensitivity analyses above show that wide ranges of such parameter choices, while generating a fairly large range of implied asset and thus equity volatilities, do not significantly affect our calculated credit yield spreads, we conclude that our choice to not match equity volatility does not significantly affect our results and conclusions.

\section{Default probability for each credit rating}

Since our calibration approach puts an emphasis on matching historically observed default probabilities, we need to ensure that our results are not overly sensitive to the default probability estimates that we use, especially given that there are reasons to believe that the estimated default probabilities reported by Moody's may not be accurate.

In Table 14, we show results of our calculation when we deviate from our base case by increasing the assumed target default probability of each credit rating by $50 \%$ (of the base case value). Our calculated credit yield spreads are sensitive to this change, 
but the overall quantitative effect remains too small to alter our conclusions.

\section{Average recovery rate given default}

Table 15 shows the results of our calculations when we change the average recovery rate for senior unsecured debt from $51.31 \%$ (as estimated by Moody's) in our base case to $45 \%$. This change increases our calculated credit spread, but the effect is again not large.

\section{Conclusions}

We ask how much of the historically observed corporate-Treasury yield spread is due to credit risk. This question can be best answered within the widely adopted structural framework of credit risk valuation. The literature within this framework, however, has so far failed to reach a consensus in answering this question.

We show that the structural framework of credit risk valuation can indeed provide a consistent answer to this question. We reach this conclusion by calibrating a large class of structural models - both existing and new ones - to be consistent with data on historical default loss experience. This approach has the advantage that the calculated credit yield spreads are generated by models that indeed realistically describe the actual severity of expected default loss. Although calibrated to the same level of expected default loss, different models, under very different economic assumptions, can still generate a very large range of credit risk premia that could potentially explain observed corporate yield spreads. We show, however, that these models predict fairly consistent credit risk premia under empirically reasonable parameter choices. This

allows us to reach robust conclusions on the quantitative magnitude of credit risk spreads.

We conclude that, for investment grade bonds (those with a credit rating not lower than Baa) of all maturities, credit risk accounts for only a small fraction-typically around $20 \%$, and, for Baa-rated bonds, in the $30 \%$ range - of the observed corporateTreasury yield spreads, and it accounts for a smaller fraction of the observed spreads for bonds of shorter maturities. For junk bonds, however, credit risk accounts for a much larger fraction of the observed corporate-Treasury yield spreads. 


\section{References}

Altman, E., 2001, Bankruptcy, Credit Risk and High Yield "Junk" Bonds: A Compendium of Writings, Blackwell Publishing.

Altman, E. and V. Kishore, 1996, "Almost Everything You Wanted To Know About Recoveries on Defaulted Bonds," Financial Analysts Journal, November/December, 5764.

Anderson, R., and S. Sundaresan, 1996, "Design and Valuation of Debt Contracts," Review of Financial Studies, 9, 37-68.

Anderson, R., and S. Sundaresan, 2000, "A comparative study of structural models of corporate bond yields: An exploratory investigation," Journal of Banking and Finance, $24,255-269$.

Anderson, R., S. Sundaresan, and P. Tychon, 1996, "Strategic Analysis of Contingent Claims," European Economic Review, 40, 871-881.

Anderson, T. G., L. Benzoni, and J. Lund, 2001, "An Empirical Investigation of Continuous-Time Equity Return Models," Working Paper, Northwestern University, University of Minnesota, and Aarhus School of Business.

Andrade, G. and S. Kaplan, 1998, "How Costly is Financial (Not Economic) Distress? Evidence from Highly Leveraged Transactions That Became Distressed," Journal of Finance, 53, 1443-1493.

Bhandari, C., 1988, "Debt/Equity Ratio and Expected Common Stock Returns: Empirical Evidence," Journal of Finance, 43, 507-528.

Black, F., and J. Cox, 1976, "Valuing Corporate Securities: Some Effects of Bond Indenture Provisions," Journal of Finance, 31, 351-367.

Black, F., and M. Scholes, 1973, "The Pricing of Options and Corporate Liabilities," Journal of Political Economy, 81, 637-59.

Campbell, J. Y., A. Lo and C. MacKinlay, 1997, "The Econometrics of Financial Markets," Princeton University Press.

Campbell, J. Y., and G. Taksler, 2002, "Equity Volatility and Corporate Bond Yields," working paper, Harvard University. 
Campbell, J. Y., and L. Viceira, 1999, "Consumption and Portfolio Decisions when Expected Returns are Time Varying," Quarterly Journal of Economics, 114, 433-495.

Campbell, J. Y., and M. Yogo, 2002, "Efficient Tests of Stock Return Predictability," working paper, Harvard University.

Caouette, J. B., E. I. Altman, and P. Narayanan, 1998, "Managing Credit Risk: The Next Great Financial Challenge," John Wiley \& Sons, Inc., New York.

Carey, M., and M. Hrycay, 2001, "Parameterizing Credit Risk Models with Rating Data," Journal of Banking and Finance, 25, 197-270.

Collin-Dufresne, P. and R. Goldstein, 2001, "Do Credit Spreads Reflect Stationary Leverage Ratios?," Journal of Finance, 56, 1929-1957.

Collin-Dufresne, P., R. Goldstein, and S. Martin, 2001, "The determinants of credit spread changes," Journal of Finance, 56, 2177-2208.

Crabbe, L., 1991, "Callable Corporate Bonds: A Vanishing Breed," Working Paper \#151, Board of Governors of the Federal Reserve System.

Delianedis, G. and R. Geske, 2001, "The components of corporate credit spreads: Default, recovery, tax, jumps, liquidity, and market factors," Working Paper 22-01, Anderson School, UCLA.

Dichev, I. D., 1998, "Is the Risk of Bankruptcy a Systematic Risk?" Journal of Finance, $53,1131-1147$.

Duffee, G., 1998, "The Relation Between Treasury Yields and Corporate Bond Yield Spreads," Journal of Finance, 54, 2225-2241.

Duffie, D. and D. Lando, 2001, "Term Structure of Credit Spreads with Incomplete Accounting Information," Econometrica, 69, 633-664.

Duffie, D. and K. Singleton, 1999, "Modeling Term Structure of Defaultable Bonds," Review of Financial Studies, 12, 687-720.

Elton, E., M. Gruber, D. Agrawal, and C. Mann, 2001, "Explaining the Rate Spread on Corporate Bonds," Journal of Finance, 56, 247-277.

Eom, Y. H., J. Helwege, and J. Huang, 2000, "Structural Models of Corporate Bond Pricing: An Empirical Analysis," working paper, Yonsei, Ohio State, and Penn State Universities. 
Ericsson, J. and J. Reneby, 2001, "The Valuation of Corporate Liabilities: Theory and Tests," working paper, McGill University and Stockholm School of Economics.

Fama, E. and K. French, 2002a, "Testing Trade-Off and Pecking Oder Predictions about Dividends and Debt," Review of Financial Studies, 15, 1-34.

Fama, E. and K. French, 2002b, "The Equity Premium," Journal of Finance, 57, 637-659.

Fons, J., 1994, "Using Default Rates to Model the Term Structure of Credit Risk," Financial Analysts Journal, September-October, 25-32.

Geske, R., 1977, "The Valuation of Corporate Liabilities as Compound Options," Journal of Financial and Quantitative Analysis, 541-552.

Goyal, A. and P. Santa-Clara, 2002, "Idiosyncratic Risk Matters!" Working Paper, UCLA. Ibbotson Associates, 2002, Stocks, Bonds, Bills, and Inflation, 2002 Yearbook.

Jarrow, R., and S. Turnbull, 1995, "Pricing Derivatives on Financial Securities Subject to Default Risk," Journal of Finance, 50, 53-86.

Jones, E., S. Mason, and E. Rosenfeld, 1984, "Contingent Claims Analysis of Corporate Capital Structures: An Empirical Analysis," Journal of Finance, 39, 611-625.

Kealhofer, S., and M. Kurbat, 2001, "The Default Prediction Power of the Merton Approach, Relative to Debt Ratings and Accounting Variables," working paper, KMV Corp., San Francisco, CA.

Keenan, S.C., I. Shtogrin, and J. Sobehart, 1999, "Historical Default Rates of Corporate Bond Issuers, 1920-1998," Moody's Investor's Service, January.

Kim, I.J., K. Ramaswamy, and S. Sundaresan, 1993, "Does Default Risk in Coupons Affect the Valuation of Corporate Bonds?" Financial Management, 22, 117-131.

Kou, S. G., 2002, "A Jump Diffusion Model for Option Pricing," working paper, Columbia University.

Kou, S. G., and H. Wang, 2002, "First Passage Time of a Jump Diffusion Process," working paper, Columbia University.

Leland, H., 1994, "Corporate Debt Value, Bond Covenants, and Optimal Capital Structure," Journal of Finance, 1213-1252. 
Leland, H., 1998, "Agency Costs, Risk Management, and Capital Structure," Journal of Finance, 53, 1213-1242.

Leland, H., 2002, "Predictions of Expected Default Frequencies in Structural Models of Debt," working paper, University of California at Berkeley.

Leland, H., and K. Toft, 1996, "Optimal Capital Structure, Endogenous Bankruptcy, and the Term Structure of Credit Spreads," Journal of Finance, 51, 987-1019.

Longstaff, F., and E. Schwartz, 1995, "Valuing Risky Debt: A New Approach," Journal of Finance, 789-820.

Lyden, S., and D. Saraniti, 2000, "An Empirical Examination of the Classical Theory of Corporate Security Valuation," Barclays Global Investors.

Mella-Barral, P., and W. Perraudin, 1997, "Strategic Debt Service," Journal of Finance, $52,531-566$.

Merton, R.C., 1974, "On the Pricing of Corporate Debt: The Risk Structure of Interest Rates," Journal of Finance, 29, 449-470.

Nielsen, L., J. Saa-Requejo, and P. Santa-Clara, 1993, "Default Risk and Interest Rate Risk: The Term Structure of Default Spreads," working paper, INSEAD.

Shiller, R., 1981, "Do Stock Prices Move Too Much To Be Justified By Subsequent Changes in Dividends?" American Economic Review, 71, 421-436.

Standard \& Poor's, 1999, "Corporate Ratings Criteria."

Titman, S., 2002, "The Modigliani and Miller Theorem and Market Efficiency," forthcoming Financial Managements.

Vasicek, O., 1977, "An Equilibrium Characterization of the Term Structure," Journal of Financial Economics, v5, 177-188.

Vuolteenaho, T., 2002, "What Drives Firm-Level Stock Returns?" Journal of Finance, 57, 233-264.

Zhou, C., 2001, "The Term Structure of Credit Spreads with Jump Risk," Journal of Banking \& Finance, 25, 2015-2040. 


\section{Appendix}

In this appendix we provide all the formulas for real default probabilities and bond prices for four models: CDG, LS, the mean-reverting risk premium model, and the model with a double exponential jump diffusion firm value process. The corresponding formulas for the LT and AST models are given earlier in section 2.

\section{A Formulas of Real Default Probability}

In this section we work under the physical measure $\mathbb{P}$. Let $X$ be a new process $\left(V_{t} / V_{t}^{*}\right)_{t \geq 0}$.

\section{A.1 Diffusion Models}

All of the models with a diffusion asset value process considered in this paper are special cases of the following class of 3 -factor models:

$$
\begin{aligned}
d \ln X_{t} & =\left[\left(\pi_{t}^{v}+r_{t}\right)-\delta-\sigma_{v}^{2} / 2-\mu_{k}\left(r_{t}, \ln X_{t}\right)\right] d t+\sigma_{v} d W_{t}^{v} \\
d r_{t} & =\bar{\kappa}_{r}\left(\bar{\theta}-r_{t}\right) d t+\sigma_{r} d W_{t}^{r} \\
d \pi_{t}^{v} & =\kappa_{\pi}\left(\bar{\pi}^{v}-\pi_{t}^{v}\right) d t+\sigma_{\pi} d W_{t}^{\pi}
\end{aligned}
$$

where all the parameters are as defined before, and the function $\mu_{k}$-affine in both $r$ and $\ln X$-is non-zero only when $V_{t}^{*}$ is stochastic. Note that the drift function in (28) is also affine in $\pi^{v}$, which, like $r$, is a Gaussian process. As a result, one can extend the Longstaff and Schwartz (1995) approach to the above 3-factor model and calculate its real default probabilities. Below we consider some special cases of the model.

\section{A.1.1 Constant Asset Risk Premium}

In this case $\pi_{t}^{v}=\pi^{v} \forall t$, a constant. The 3 -factor model reduces to a two-factor one, which includes both LS and CDG.

Default probabilities $Q(0, \cdot)$ can be calculated using an approach in the spirit of LS. Namely,

$$
Q(0, U)=\sum_{i=1}^{n} q\left(t_{i} ; t_{0}\right), \quad t_{i}=i U / n, \quad U \in(0, T],
$$

where for $i=1,2, \ldots, n$,

$$
q\left(t_{i} ; t_{0}\right)=\frac{N\left(a\left(t_{i} ; t_{0}\right)\right)-\sum_{j=1}^{i-1} q\left(t_{j-\frac{1}{2}} ; t_{0}\right) N\left(b\left(t_{i} ; t_{j-\frac{1}{2}}\right)\right)}{N\left(b\left(t_{i} ; t_{i-\frac{1}{2}}\right)\right)}
$$




$$
\begin{aligned}
& a\left(t_{i} ; t_{0}\right)=-\frac{M\left(t_{i}, T \mid X_{0}, r_{0}\right)}{\sqrt{S\left(t_{i} \mid X_{0}, r_{0}\right)}} \\
& b\left(t_{i} ; t_{j}\right)=-\frac{M\left(t_{i}, T \mid X_{t_{j}}\right)}{\sqrt{S\left(t_{i} \mid X_{t_{j}}\right)}}
\end{aligned}
$$

and where the sum on the RHS of (32) is defined to be zero when $i=1$, and

$$
\begin{aligned}
M\left(t, T \mid X_{0}, r_{0}\right) & \equiv E_{0}\left[\ln X_{t}\right] \\
S\left(t \mid X_{0}, r_{0}\right) & \equiv \operatorname{Var}_{0}\left[\ln X_{t}\right] \\
M\left(t, T \mid X_{u}\right) & =M\left(t, T \mid X_{0}, r_{0}\right)-M\left(u, T \mid X_{0}, r_{0}\right) \frac{\operatorname{Cov}_{0}\left[\ln X_{t}, \ln X_{u}\right]}{S\left(u \mid X_{0}, r_{0}\right)}, u \in\left(t_{0}, t\right) \\
S\left(t \mid X_{u}\right) & =S\left(t \mid X_{0}, r_{0}\right)-\frac{\operatorname{Cov}_{0}\left[\ln X_{t}, \ln X_{u}\right]^{2}}{S\left(u \mid X_{0}, r_{0}\right)}, u \in\left(t_{0}, t\right)
\end{aligned}
$$

Notice that we follow CDG to discretize at $t_{j-\frac{1}{2}}, j=1, \ldots, i-1$, on the RHS of (32). One can see that the implementation of this approach to computing $Q(0, \cdot)$ amounts to calculating the mean $M\left(t, T \mid X_{0}, r_{0}\right)$ and the covariance $\operatorname{Cov}_{0}\left[\ln X_{t}, \ln X_{u}\right], \forall u \leq t \leq T$.

We now use $(31)-(38)$ to derive the default probability $Q(0, \cdot)$ for the CDG model. This derivation method is different from that used in the original CDG model, but we use it here because this method conveniently covers the 2-factor LS model and our time-varying risk premium model as two special cases.

\section{The Collin-Dufresne and Goldstein Model}

In the CDG model,

$$
\mu_{k}\left(r_{t}, \ln X_{t}\right)=\kappa_{\ell}\left[\ln X_{t}-\nu-\phi\left(r_{t}-\theta\right)\right]
$$

where $\kappa_{\ell}, \nu$, and $\phi$ are constants. One has from (28) and (29) that

$$
\begin{aligned}
e^{\kappa_{\ell} t} \ln X_{t} & =\ln X_{0}+\left(\pi^{v}+\bar{\nu} \kappa_{\ell}\right) \frac{e^{\kappa_{\ell} t}-1}{\kappa_{\ell}}+\int_{0}^{t}\left(1+\phi \kappa_{\ell}\right) r_{u} e^{\kappa_{\ell} u} d u+\int_{0}^{t} \sigma_{v} e^{\kappa_{\ell} u} d W_{u}^{v} \\
r_{t} & =r_{0} e^{-\beta t}+\frac{\bar{\alpha}}{\beta}\left(1-e^{-\beta t}\right)+\sigma_{r} e^{-\beta t} \int_{0}^{t} e^{\beta u} d W_{u}^{r}
\end{aligned}
$$

where $\bar{\alpha}=\bar{\kappa} \bar{\theta}, \beta=\bar{\kappa}$, and

$$
\bar{\nu} \equiv(\nu-\phi \theta)-\left(\delta+\sigma_{v}^{2} / 2\right) / \kappa_{\ell}
$$

It follows that

$$
\begin{aligned}
e^{\kappa_{\ell} t} E_{0}\left[\ln X_{t}\right]= & \ln X_{0}+\left[\left(\pi^{v}+\bar{\nu} \kappa_{\ell}\right)+\left(1+\kappa_{\ell} \phi\right) \frac{\bar{\alpha}}{\beta}\right] \frac{e^{\kappa_{\ell} t}-1}{\kappa_{\ell}} \\
& +\left(1+\kappa_{\ell} \phi\right)\left(r_{0}-\frac{\bar{\alpha}}{\beta}\right) \frac{e^{\left(\kappa_{\ell}-\beta\right) t}-1}{\kappa_{\ell}-\beta}
\end{aligned}
$$


and

$$
\begin{array}{cl}
\operatorname{Cov}_{0}\left[\ln X_{t}, \ln X_{u}\right] e^{\kappa_{\ell}(t+u)}= & \left(\equiv I_{1}\right) \\
\sigma_{v}^{2} E_{0}\left[\int_{0}^{t} e^{\kappa_{\ell} v} d Z_{v} \int_{0}^{u} e^{\kappa_{\ell} v} d Z_{v}\right] & \left(\equiv I_{2}\right) \\
+\sigma_{v}\left(1+\phi \kappa_{\ell}\right) E_{0}\left[\int_{0}^{t} e^{\kappa_{\ell} v} d Z_{v} \int_{0}^{u} e^{\kappa_{\ell} v} r_{v} d v\right] & \left(\equiv I_{3}\right) \\
+ & \sigma_{v}\left(1+\phi \kappa_{\ell}\right) E_{0}\left[\int_{0}^{u} e^{\kappa_{\ell} v} d Z_{v} \int_{0}^{t} e^{\kappa_{\ell} v} r_{v} d v\right] \\
& +\left(1+\phi \kappa_{\ell}\right)^{2} \operatorname{Cov}_{0}\left[\int_{0}^{t} e^{\kappa_{\ell} v} r_{v} d v, \int_{0}^{u} e^{\kappa_{\ell} v} r_{v} d v\right]
\end{array}
$$

One can show that $\forall t \geq u$,

$$
\begin{aligned}
I_{1}= & \frac{\sigma_{v}^{2}}{2 \kappa_{\ell}}\left(e^{2 \kappa_{\ell} u}-1\right) \\
I_{2}= & \left(1+\phi \kappa_{\ell}\right) \frac{\rho_{r V} \sigma_{v} \sigma_{r}}{\kappa_{\ell}+\beta}\left[\frac{e^{2 \kappa_{\ell} u}-1}{2 \kappa_{\ell}}-\frac{e^{\left(\kappa_{\ell}-\beta\right) u}-1}{\kappa_{\ell}-\beta}\right] \\
I_{3}= & \left(1+\phi \kappa_{\ell}\right) \frac{\rho_{r V} \sigma_{v} \sigma_{r}}{\kappa_{\ell}+\beta}\left[\frac{1-e^{\left(\kappa_{\ell}-\beta\right) t}}{\kappa_{\ell}-\beta}+\frac{e^{2 \kappa_{\ell} u}-1}{2 \kappa_{\ell}}+e^{\left(\kappa_{\ell}+\beta\right) u} \frac{e^{\left(\kappa_{\ell}-\beta\right) t}-e^{\left(\kappa_{\ell}-\beta\right) u}}{\kappa_{\ell}-\beta}\right] \\
I_{4}= & \left(1+\phi \kappa_{\ell}\right)^{2} \frac{\sigma_{r}^{2}}{2 \beta}\left[-\frac{\left(e^{\left(\kappa_{\ell}-\beta\right) t}-1\right)\left(e^{\left(\kappa_{\ell}-\beta\right) u}-1\right)}{\left(\kappa_{\ell}-\beta\right)^{2}}+\left(e^{\left(\kappa_{\ell}+\beta\right) u}-1\right) \frac{e^{\left(\kappa_{\ell}-\beta\right) t}-e^{\left(\kappa_{\ell}-\beta\right) u}}{\kappa_{\ell}^{2}-\beta^{2}}\right. \\
& \left.-\frac{\beta}{\kappa_{\ell}^{2}-\beta^{2}} \frac{e^{2 \kappa_{\ell} u}-1}{\kappa_{\ell}}+\frac{1}{\kappa_{\ell}^{2}-\beta^{2}}\left(1-2 e^{\left(\kappa_{\ell}-\beta\right) u}+e^{2 \kappa_{\ell} u}\right)\right]
\end{aligned}
$$

\section{The Longstaff and Schwartz Model}

The formulas in this model can be obtained by setting $\kappa_{\ell}$ to zero in CDG.

\section{A.1.2 A Mean-Reverting Asset Risk Premium}

For simplicity, we assume in this subsection that the interest rate is constant (and thus $\phi=0)$. In this case, the 3 -factor model also reduces to a two-factor one. We can still use Eqs. (32)-(38) to calculate $Q(0, \cdot)$ but need to recalculate $E_{0}\left[\ln X_{t}\right]$ and $\operatorname{Cov}_{0}\left[\ln X_{t}, \ln X_{u}\right]$ using $X$ and $\pi^{v}$ as the state variables.

We have from (28) and (30) that

$$
\begin{aligned}
e^{\kappa_{\ell} t} \ln X_{t} & =\ln X_{0}+\left(r_{0}+\bar{\nu} \kappa_{\ell}\right) \frac{e^{\kappa_{\ell} t}-1}{\kappa_{\ell}}+\int_{0}^{t} \pi_{u}^{v} e^{\kappa_{\ell} u} d u+\int_{0}^{t} \sigma_{v} e^{\kappa_{\ell} u} d W_{u}^{v} \\
\pi_{t}^{v} & =\pi_{0}^{v} e^{-\beta_{\pi} t}+\frac{\alpha_{\pi}}{\beta_{\pi}}\left(1-e^{-\beta_{\pi} t}\right)+\sigma_{\pi} e^{-\beta_{\pi} t} \int_{0}^{t} e^{\beta_{\pi} u} d W_{u}^{\pi}
\end{aligned}
$$


where $\alpha_{\pi}=\kappa_{\pi} \bar{\pi}^{v}$ and $\beta_{\pi}=\kappa_{\pi}$. In comparison with (40) and (41), it is easy to see that $E_{0}\left[\ln X_{t}\right]$ and $\operatorname{Cov}_{0}\left[\ln X_{t}, \ln X_{u}\right]$ (and hence $Q(0, \cdot)$ ) can be obtained from (43) and (44) via the transform $\left(\pi_{0}^{v}, \phi, r_{0}, \bar{\alpha}, \beta, \rho_{r V}\right) \rightarrow\left(r_{0}, 0, \pi_{0}^{v}, \alpha_{\pi}, \beta_{\pi}, \rho_{\pi V}\right)$. For instance,

$$
e^{\kappa_{\ell} t} E_{0}\left[\ln X_{t}\right]=\ln X_{0}+\left(r_{0}+\bar{\nu} \kappa_{\ell}+\frac{\alpha_{\pi}}{\beta_{\pi}}\right) \frac{e^{\kappa_{\ell} t}-1}{\kappa_{\ell}}+\left(\pi^{v}-\frac{\alpha_{\pi}}{\beta_{\pi}}\right) \frac{e^{\left(\kappa_{\ell}-\beta_{\pi}\right) t}-1}{\kappa_{\ell}-\beta_{\pi}}
$$

\section{A.2 The Jump Diffusion Model}

In this subsection, the interest rate and all the risk premia are assumed to be constant. The default boundary is assumed to be flat at $V^{*}$. Under $\mathbb{P}$,

$$
d \ln V_{t}=\left(\pi^{v}+r-\delta-\frac{\sigma_{v}^{2}}{2}\right) d t+\sigma_{v} d W_{t}^{v}+d\left[\sum_{i=1}^{N_{t}} Z_{i}\right]-\lambda \xi d t
$$

with the distribution of the jump process specified in section 2 .

Consider the Laplace transform of $Q(0, \cdot)$ as defined by

$$
\widehat{Q}\left(s ; t_{0}\right)=\int_{0}^{\infty} e^{-s t} Q(0, t) d t
$$

An analytic solution for $\widehat{Q}\left(s ; t_{0}\right)$ was obtained by Kou and Wang (2002, Theorem 4.1). Let $x_{b} \equiv \ln \left(V_{0} / V^{*}\right)$ and $\mu_{x} \equiv-\left(\pi_{0}^{v}+r-\delta-\sigma_{v}^{2} / 2\right)$, we have

$$
\widehat{Q}\left(s ; t_{0}\right)=\frac{\eta_{u}-y_{1, s}}{s \eta_{u}} \frac{y_{2, s}}{y_{2, s}-y_{1, s}} e^{-x_{b} y_{1, s}}+\frac{y_{2, s}-\eta_{u}}{s \eta_{u}} \frac{y_{1, s}}{y_{2, s}-y_{1, s}} e^{-x_{b} y_{2, s}}
$$

where $y_{1, s}$ and $y_{2, s}$ are the only two positive roots for the following equation

$$
\mu_{x} y+\frac{1}{2} \sigma_{v}^{2} y^{2}+\lambda\left(\frac{p_{u} \eta_{u}}{\eta_{u}-y}+\frac{p_{d} \eta_{d}}{\eta_{d}+y}-1\right)-s=0
$$

Given $\widehat{Q}\left(s ; t_{0}\right) \forall s>0$, we then follow Kou and Wang (2002) to calculate numerically $Q(0, \cdot)$ using the Gaver-Stehfest algorithm for Laplace inversion. For brevity, the details of this implementation method are omitted here but can be found in Kou and Wang (2002).

\section{B Formulas of Defaultable Bond Prices}

Consider a defaultable bond with maturity $T$ and unit face value that pays semi-annual coupons at an annual rate of $c$. For simplicity, assume $2 T$ is an integer. Let $T_{n}, n=$ $1, \ldots, 2 T$, be the $n$th coupon date. In all of the four models considered in the appendix, the value of a defaultable bond that pays semi-annual coupons is given by

$$
P_{0, T}=\left(\frac{c}{2}\right) \sum_{i=1}^{2 T-1} D\left(0, T_{i}\right)\left[1-w_{\ell} Q^{T_{i}}\left(0, T_{i}\right)\right]+\left(1+\frac{c}{2}\right) D(0, T)\left[1-w_{\ell} Q^{T}(0, T)\right]
$$


where $D(0, \cdot)$ denotes the value of a default-free zero-coupon bond given by the Vasicek (1977) model, $Q^{T_{i}}\left(0, T_{i}\right)$ represents the time- 0 default probability over $\left(0, T_{i}\right]$ under the $T_{i}$-forward measure, and $w_{\ell}$, the loss rate, equals $1-w$. (Here, the $T_{i}$-forward measure is induced by using $D\left(0, T_{i}\right)$ as the numeraire.) It is easy to see from (52) that once $\left(Q^{T_{i}}(0, \cdot)\right)_{i}$ are known, the bond price $P_{0, T}$ is easy to calculate.

\section{B.1 Diffusion Models}

Eqs. (32)-(38) can still be used to calculate the $T_{i}$-forward default probabilities provided that all the expectations there are done under the $T$-forward measure.

Consider under the $T$-forward measure:

$$
\begin{aligned}
d \ln X_{t} & =\left[\left(1+\phi \kappa_{\ell}\right) r_{t}+\kappa_{\ell} \bar{\nu}-\kappa_{\ell} \ln X_{t}-\rho_{r} \sigma_{v} \sigma_{r} B(t, T)\right] d t+\sigma_{v} d W_{t}^{v \mathbb{F}_{T}} \\
d r_{t} & =\left(\alpha-\beta r_{t}-\sigma_{r}^{2} B(t, T)\right) d t+\sigma_{r} d W_{t}^{r \mathbb{F}_{T}}
\end{aligned}
$$

where the LS notation is used for comparison: $\alpha=\kappa_{r} \theta, \beta=\kappa_{r}$, and

$$
B(t, T)=\frac{1}{\beta}\left(1-e^{-\beta(T-t)}\right)
$$

\section{B.1.1 The Collin-Dufresne and Goldstein Model}

The mean $M\left(t, T \mid X_{0}, r_{0}\right)$ can be obtained from the following result

$$
\begin{aligned}
e^{\kappa_{\ell} t} E_{0}^{\mathbb{F}_{T}}\left[\ln X_{t}\right]= & \ln X_{0}+\bar{\nu}\left(e^{\kappa_{\ell} t}-1\right)+\int_{0}^{t}\left(1+\phi \kappa_{\ell}\right) e^{\kappa_{\ell} u} E_{0}^{\mathbb{F}_{T}}\left[r_{u}\right] d u \\
& -\frac{\rho_{r V} \sigma_{v} \sigma_{r}}{\beta}\left[\frac{e^{\kappa_{\ell} t}-1}{\kappa_{\ell}}-e^{\beta T} \frac{e^{\left(\kappa_{\ell}+\beta\right) t}-1}{\kappa_{\ell}+\beta}\right]
\end{aligned}
$$

where

$$
\begin{aligned}
E_{0}^{\mathbb{F}_{T}}\left[r_{u}\right]= & r_{0} e^{-\beta t}+\left(\frac{\alpha}{\beta}-\frac{\sigma_{r}^{2}}{\beta^{2}}\right)\left(1-e^{-\beta t}\right)+\frac{\sigma_{r}^{2}}{2 \beta^{2}} e^{-\beta T}\left(e^{\beta t}-e^{-\beta t}\right) \\
& +\sigma_{r} e^{-\beta t} \int_{0}^{t} e^{\beta u} d W_{u}^{r \mathbb{F}_{T}}
\end{aligned}
$$

Since here $\operatorname{Cov}_{0}^{\mathbb{F}_{T}}\left[\ln X_{t}, \ln X_{u}\right]=\operatorname{Cov}_{0}\left[\ln X_{t}, \ln X_{u}\right]$, we are done.

\section{B.1.2 The Longstaff-Schwartz Model}

Again, the LS price of a defaultable bond can be obtained by setting $\kappa_{\ell}$ to zero in CDG. 


\section{B.1.3 A Mean-Reverting Asset Risk Premium}

In terms of pricing, this model is equivalent to a one-factor CDG or LS depending on $\kappa_{\ell}$, since the specification of the drift function under the physical measure has no impact on the pricing.

\section{B.2 The Jump Diffusion Model}

Default probabilities under the $Q$-measure can be obtained from their counterparties under the $P$-measure by the transform $\left(\pi_{0}^{v}, \eta_{u}, \eta_{d}, p_{u}, \lambda\right) \rightarrow\left(0, \eta_{u}^{Q}, \eta_{d}^{Q}, p_{u}^{Q}, \lambda^{Q}\right)$.

\section{Relating the Equity Premium to the Asset Risk Premium}

In this section, we briefly describe how we relate the asset premium to the equity premium. We use the case of a semi-annual coupon bond for illustration.

Given the asset premium $\pi^{v}$, the following formula is used to back out the equity premium $\pi^{e}$

$$
\pi^{v} V_{t}=\pi^{e}\left(V_{t}-P_{0, t}\right)+\pi^{b} P_{0, t}
$$

where $\pi^{b}$ denotes the bond risk premium. To relate $\pi^{v}$ to $\pi^{e}$, we need to know $\pi^{b}$.

Below we use a simple method to estimate the risk premium of a risky bond. Let $Q(0, t)$ be the cumulative real default probability over $(0, t]$ as before. We have

$$
\begin{aligned}
P_{0, t} & =\sum_{i=1}^{2 T} \frac{\left[c\left(1-Q\left(0, t_{i}\right)\right) / 2+\hat{w} c Q\left(0, t_{i}\right) / 2\right]}{\left(1+y_{b} / 2\right)^{i}}+\frac{(1-Q(0, T))+\hat{w} Q(0, T)}{\left(1+y_{b} / 2\right)^{2 T}} \\
& =\sum_{i=1}^{2 T} \frac{c\left[1-(1-\hat{w}) Q\left(0, t_{i}\right)\right]}{2\left(1+y_{b} / 2\right)^{i}}+\frac{[1-(1-\hat{w}) Q(0, T)]}{\left(1+y_{b} / 2\right)^{2 T}}
\end{aligned}
$$

where $c$ is the annual coupon payment and $\hat{w}$ is the recovery rate (as a fraction of the bond face value). Given the bond price, the above equation can be used to solve for $y_{b}$. The spread of $y_{b}$ over a comparable default-free bond is then used as a proxy for the risk premium of a bond. 


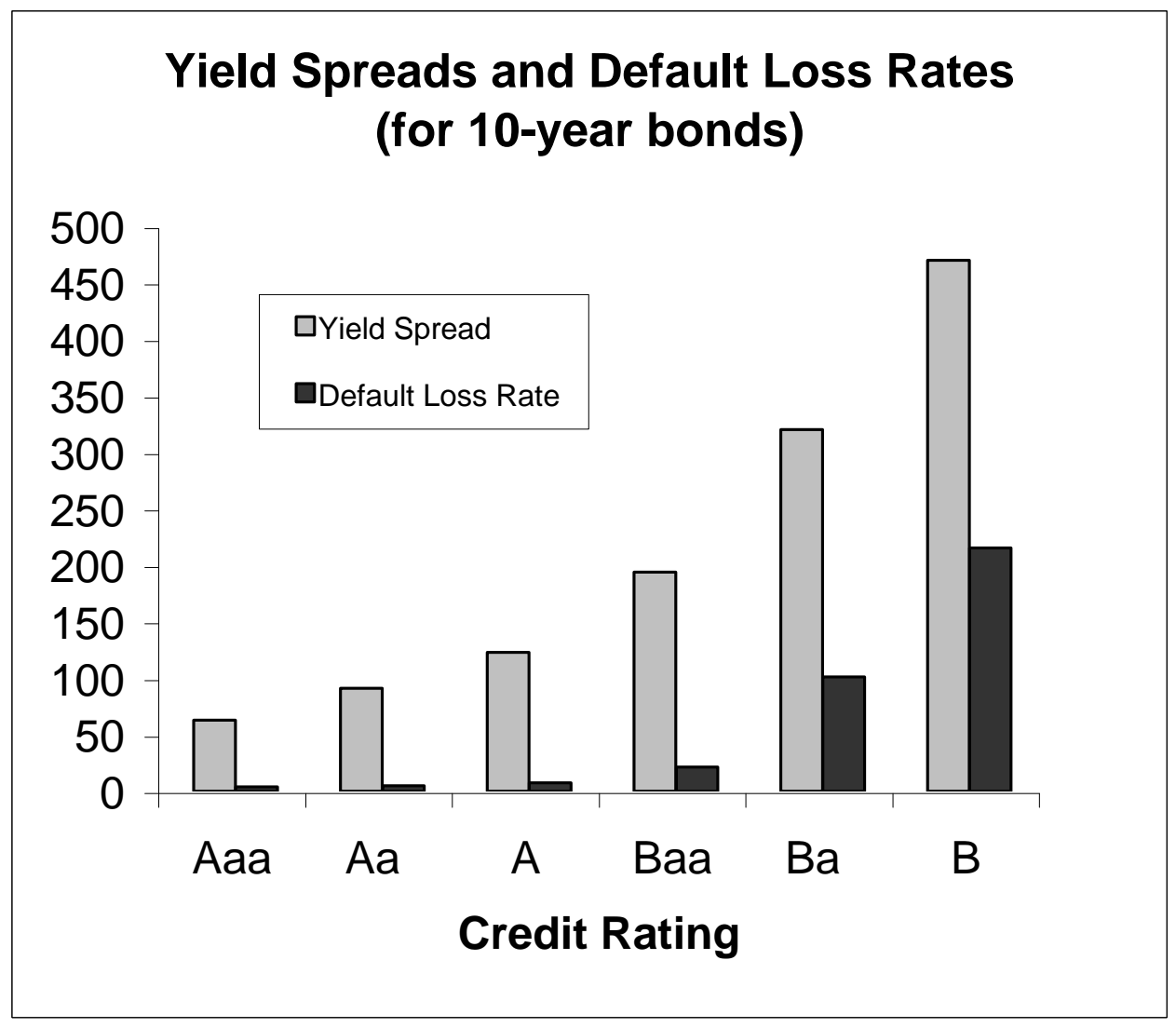

Figure 1: Historical average yield spreads (in basis points) for 10-year bonds of each credit rating (from the Lehman bond index data), and the average default loss rates (from Moody's report by Keenan, Shtogrin, and Sobehart (1999)) for corporate bonds with each initial credit rating over a 10-year time interval. 


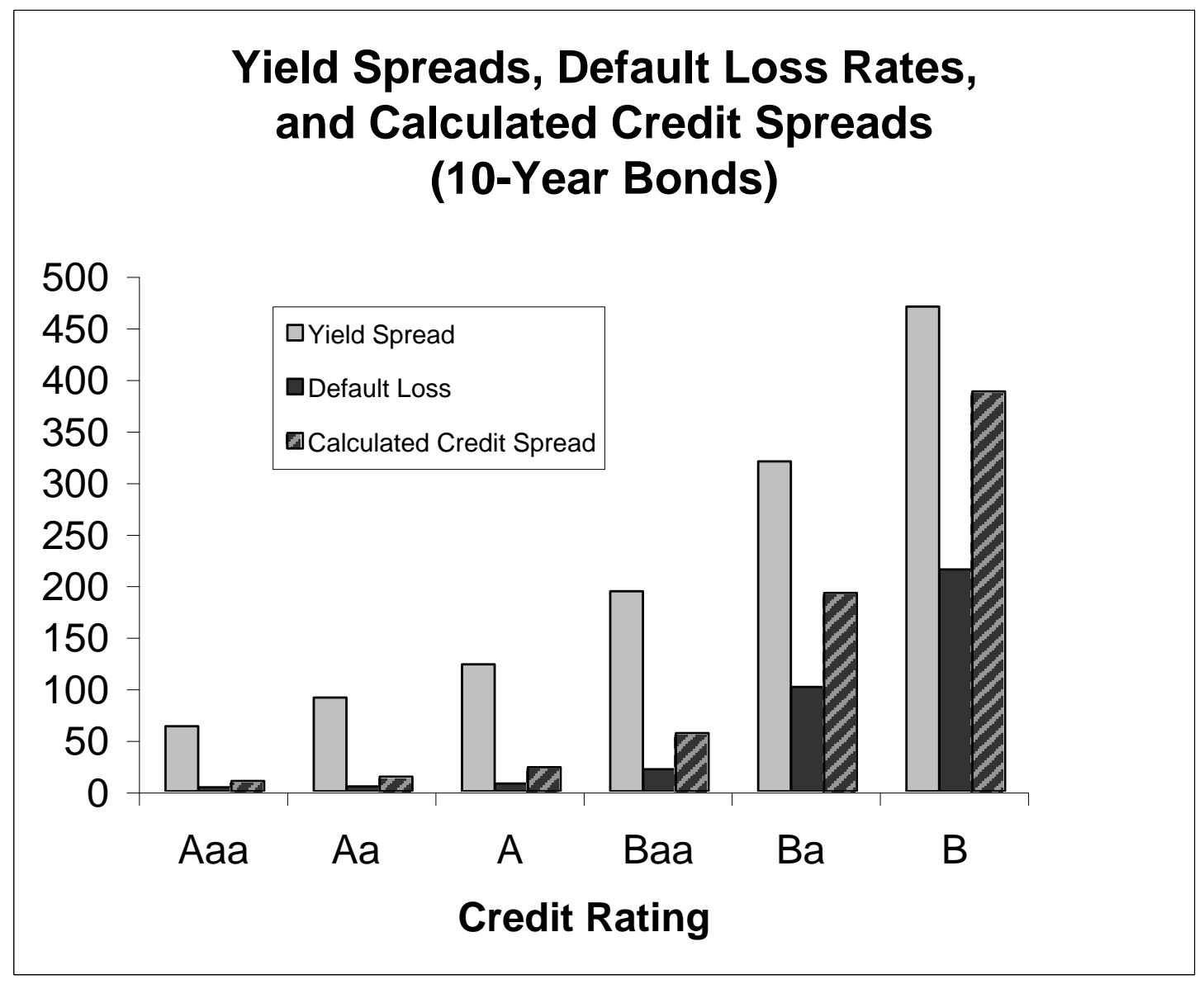

Figure 2: Historical average yield spreads (in basis points) for 10-year bonds of each credit rating (from the Lehman bond index data), the average default loss rates (from Moody's report by Keenan, Shtogrin, and Sobehart (1999)) for corporate bonds with each initial credit rating over a 10-year time interval, and the calculated credit spreads for 10-year bonds of each credit rating under the base case. 


\section{Table 1: The Base Case: Parameter Value Choices}

\begin{tabular}{|c|c|c|c|c|c|c|c|c|}
\hline (1) & (2) & (3) & (4) & $(5)$ & (6) & (7) & $(8)$ & (9) \\
\hline \multirow{3}{*}{$\begin{array}{l}\text { Credit } \\
\text { rating }\end{array}$} & \multicolumn{6}{|c|}{ Target } & & \\
\hline & \multirow{2}{*}{$\begin{array}{c}\text { Leverage } \\
\text { ratio } \\
(\%)\end{array}$} & \multirow{2}{*}{$\begin{array}{c}\text { Equity } \\
\text { premium } \\
(\%)\end{array}$} & \multicolumn{3}{|c|}{$\begin{array}{c}\text { Cumulative } \\
\text { default prob. (\%) }\end{array}$} & \multirow{2}{*}{$\begin{array}{c}\text { Recovery } \\
\text { rate } \\
(\%) \\
\end{array}$} & \multicolumn{2}{|c|}{$\begin{array}{l}\text { Avg. yld. } \\
\text { spreads (\%) }\end{array}$} \\
\hline & & & $1 \mathrm{yr}$. & $4 \mathrm{yrs}$. & $10 \mathrm{yrs}$. & & 4 yrs. & $10 \mathrm{yrs}$. \\
\hline Aaa & 13.08 & 5.38 & 0.00 & 0.04 & 0.77 & 51.31 & 0.55 & 0.63 \\
\hline $\mathrm{Aa}$ & 21.18 & 5.60 & 0.03 & 0.23 & 0.99 & 51.31 & 0.65 & 0.91 \\
\hline $\mathrm{A}$ & 31.98 & 5.99 & 0.01 & 0.35 & 1.55 & 51.31 & 0.96 & 1.23 \\
\hline Baa & 43.28 & 6.55 & 0.12 & 1.24 & 4.39 & 51.31 & 1.58 & 1.94 \\
\hline $\mathrm{Ba}$ & 53.53 & 7.30 & 1.29 & 8.51 & 20.63 & 51.31 & 3.20 & 3.20 \\
\hline B & 65.70 & 8.76 & 6.47 & 23.32 & 43.91 & 51.31 & 4.70 & 4.70 \\
\hline
\end{tabular}

Table 1 shows the target parameters for calibration and the historical average yield spreads for each class of credit rating for our base case. Leverage ratios are from Standard \& Poor's (1999). Equity premia estimates are based on regression results in Bhandari (1988). Historical default rates and average recovery rates are from the Moody's report of Keenan, Shtogrin, and Sobenhart (1999). Average yield spreads for investment-grade bonds are from the Lehman bond index data and from Duffee (1998). Average yield spreads for junk bonds are based on Caouette, Altman, and Narayanan (1998). 


\section{Table 2: The Base Case: Results from the LS Model}

Panel A: Maturity $=10$ years

\begin{tabular}{|c|c|c|c|c|c|c|c|c|}
\hline (1) & $(2)$ & (3) & (4) & $(5)$ & (6) & (7) & (8) & (9) \\
\hline \multirow{3}{*}{$\begin{array}{l}\text { Credit } \\
\text { Rating }\end{array}$} & \multicolumn{3}{|c|}{ Target } & \multicolumn{2}{|c|}{ Implied } & & & \\
\hline & T & Eruitu & Cum. & $A_{\text {cont }}$ & Asset & Calc & Avg & $\%$ of \\
\hline & Ratio & Prem & Prob. & Vol. & Prem & Spread & Spread & due to \\
\hline Aaa & 13.1 & 5.38 & 0.77 & 32.1 & 4.96 & 10.0 & 63 & 15.8 \\
\hline $\mathrm{Aa}$ & 21.2 & 5.60 & 0.99 & 28.4 & 4.91 & 14.2 & 91 & 15.6 \\
\hline $\mathrm{A}$ & 32.0 & 5.99 & 1.55 & 25.6 & 4.89 & 23.3 & 123 & 19.0 \\
\hline Baa & 43.3 & 6.55 & 4.39 & 25.8 & 5.01 & 56.5 & 194 & 29.1 \\
\hline $\mathrm{Ba}$ & 53.5 & 7.30 & 20.63 & 32.4 & 5.48 & 192.3 & 320 & 60.1 \\
\hline B & 65.7 & 8.76 & 43.91 & 39.5 & 6.46 & 387.8 & 470 & 82.5 \\
\hline
\end{tabular}

Panel B: Maturity $=4$ years

\begin{tabular}{ccccccccc}
\hline \hline Aaa & 13.1 & 5.38 & 0.04 & 36.2 & 4.95 & 1.1 & 55 & 2.1 \\
Aa & 21.2 & 5.60 & 0.23 & 34.4 & 4.90 & 6.0 & 65 & 9.2 \\
A & 32.0 & 5.99 & 0.35 & 29.8 & 4.85 & 9.9 & 96 & 10.3 \\
Baa & 43.3 & 6.55 & 1.24 & 28.9 & 4.91 & 32.0 & 158 & 20.3 \\
Ba & 53.5 & 7.30 & 8.51 & 34.3 & 5.29 & 172.3 & 320 & 53.9 \\
B & 65.7 & 8.76 & 23.32 & 39.6 & 6.25 & 445.7 & 470 & 94.8 \\
\hline
\end{tabular}

Panel C: Maturity $=1$ year

\begin{tabular}{ccccccc}
\hline \hline $\mathrm{Aa}$ & 21.2 & 5.60 & 0.03 & 54.9 & 4.89 & 2.0 \\
$\mathrm{~A}$ & 32.0 & 5.99 & 0.01 & 42.0 & 4.84 & 0.8 \\
$\mathrm{Baa}$ & 43.3 & 6.55 & 0.12 & 41.2 & 4.86 & 8.7 \\
$\mathrm{Ba}$ & 53.5 & 7.30 & 1.29 & 44.6 & 5.04 & 85.0 \\
$\mathrm{~B}$ & 65.7 & 8.76 & 6.47 & 48.6 & 5.74 & 411.9 \\
\hline
\end{tabular}

Table 2 reports calibration results and calculated credit yield spreads for three maturities in the base case using the Longstaff and Schwartz (1995) model. For bonds of each credit rating and maturity, the model calibrated to match the target initial leverage ratio (column 2), equity premium (column 3), and cumulative default probability until bond maturity (column 4) is shown to have the implied asset volatility and the asset risk premium given in columns 5 and 6 . The credit yield spreads calculated from such calibrated models (column 7) are also shown as a percentage (column 9) of historically observed yield spreads for the bonds (column 8). Parameter choices are as follows: coupon rate is $8.13 \%$; the asset payout ratio $\delta=6 \%$; the interest rate is constant at $8 \%$; the default boundary $V^{*}$ equals $60 \%$ of the total face value of the firms' bonds outstanding; and the recovery rate given default is fixed at $51.31 \%$. 


\section{Table 3: Effects of Stochastic Interest Rates}

$$
\text { Panel A: Maturity = } 10 \text { years }
$$

\begin{tabular}{|c|c|c|c|c|c|c|c|c|}
\hline$(1)$ & $(2)$ & $(3)$ & $(4)$ & $(5)$ & $(6)$ & $(7)$ & $(8)$ & $(9)$ \\
\hline & \multicolumn{3}{|c|}{ Target } & \multicolumn{2}{|c|}{ Implied } & & & \\
\hline Credit & Leverage & Equity & $\begin{array}{c}\text { Cum. } \\
\text { Default }\end{array}$ & Asset & $\begin{array}{c}\text { Asset } \\
\text { Risk }\end{array}$ & $\begin{array}{c}\text { Calc } \\
\text { Credit }\end{array}$ & $\begin{array}{l}\text { Avg } \\
\text { Yield }\end{array}$ & $\begin{array}{c}\% \text { of } \\
\text { Spread }\end{array}$ \\
\hline Rating & $\begin{array}{c}\text { Ratio } \\
(\%)\end{array}$ & $\begin{array}{c}\text { Prem } \\
(\%)\end{array}$ & $\begin{array}{c}\text { Prob. } \\
(\%)\end{array}$ & $\begin{array}{l}\text { Vol. } \\
(\%)\end{array}$ & $\begin{array}{c}\text { Prem } \\
(\%)\end{array}$ & $\begin{array}{c}\text { Spread } \\
\text { (bps) }\end{array}$ & $\begin{array}{c}\text { Spread } \\
\text { (bps) }\end{array}$ & $\begin{array}{l}\text { due to } \\
\text { Default }\end{array}$ \\
\hline Aaa & 13.1 & 5.38 & 0.77 & 31.5 & 4.99 & 6.0 & 63 & 9.6 \\
\hline $\mathrm{Aa}$ & 21.2 & 5.60 & 0.99 & 27.5 & 4.95 & 8.6 & 91 & 9.4 \\
\hline $\mathrm{A}$ & 32.0 & 5.99 & 1.55 & 24.5 & 4.94 & 14.5 & 123 & 11.8 \\
\hline Baa & 43.3 & 6.55 & 4.39 & 24.7 & 5.05 & 38.6 & 194 & 19.9 \\
\hline $\mathrm{Ba}$ & 53.5 & 7.30 & 20.63 & 31.3 & 5.47 & 153.9 & 320 & 48.1 \\
\hline B & 65.7 & 8.76 & 43.91 & 38.4 & 6.42 & 341.9 & 470 & 72.8 \\
\hline
\end{tabular}

Panel B: Maturity $=4$ years

\begin{tabular}{ccccccccc}
\hline \hline Aaa & 13.1 & 5.38 & 0.04 & 36.6 & 4.96 & 0.8 & 55 & 1.5 \\
$\mathrm{Aa}$ & 21.2 & 5.60 & 0.23 & 34.8 & 4.91 & 4.6 & 65 & 7.0 \\
$\mathrm{~A}$ & 32.0 & 5.99 & 0.35 & 30.0 & 4.88 & 7.5 & 96 & 7.8 \\
$\mathrm{Baa}$ & 43.3 & 6.55 & 1.24 & 29.1 & 4.94 & 25.4 & 158 & 16.1 \\
$\mathrm{Ba}$ & 53.5 & 7.30 & 8.51 & 34.3 & 5.26 & 149.2 & 320 & 46.6 \\
$\mathrm{~B}$ & 65.7 & 8.76 & 23.32 & 39.3 & 6.15 & 406.0 & 470 & 86.4 \\
\hline
\end{tabular}

Table 3 reports calibration results and calculated credit yield spreads for two maturities in the case of stochastic interest rates, implemented by using the Longstaff and Schwartz (1995) model. The setup is otherwise identical to that of the base case. For bonds of each credit rating and maturity, the model calibrated to match the target initial leverage ratio (column 2), equity premium (column 3), and cumulative default probability until bond maturity (column 4) is shown to have the implied asset volatility and the asset risk premium given in columns 5 and 6 . The credit yield spreads calculated from such calibrated models (column 7) are also shown as a percentage (column 9) of historically observed yield spreads for the bonds (column 8). Parameter choices are as follows: the coupon rate is $8.162 \%$; the asset payout ratio $\delta=6 \%$; the default boundary $V^{*}$ equals $60 \%$ of the total face value of the firms' bonds outstanding; and the recovery rate given default is fixed at $51.31 \%$. The parameters for the interest rate process are $r_{0}=8 \%, \kappa_{r}=0.226, \theta=0.113, \sigma_{r}=4.68 \%$, and $\pi_{0}^{r}=-0.248$. The correlation coefficient $\rho_{r V}$ is chosen to be -0.25 . 


\section{Table 4: Endogenous Default with the Leland-Toft Model}

\begin{tabular}{|c|c|c|c|c|c|c|c|c|c|}
\hline$(1)$ & $(2)$ & $(3)$ & (4) & $(5)$ & $(6)$ & $(7)$ & $(8)$ & $(9)$ & $(10)$ \\
\hline \multirow{4}{*}{$\begin{array}{l}\text { Credit } \\
\text { Rating }\end{array}$} & \multicolumn{3}{|c|}{ Target } & \multicolumn{3}{|c|}{ Implied } & \multirow{4}{*}{$\begin{array}{c}\text { Calc } \\
\text { Credit } \\
\text { Spread } \\
\text { (bp) }\end{array}$} & \multirow{4}{*}{$\begin{array}{c}\text { Avg } \\
\text { Yield } \\
\text { Spread } \\
\text { (bp) }\end{array}$} & \multirow{4}{*}{$\begin{array}{c}\% \text { of } \\
\text { Spread } \\
\text { due to } \\
\text { default }\end{array}$} \\
\hline & & & Cum. & & & $\begin{array}{l}\text { Asset } \\
\text { Bisk }\end{array}$ & & & \\
\hline & Leverage & Equity & Default & Recovery & Asset & Risk & & & \\
\hline & $\begin{array}{c}\text { Ratio } \\
(\%)\end{array}$ & $\begin{array}{c}\text { Prem } \\
(\%) \\
\end{array}$ & $\begin{array}{c}\text { Prob } \\
(\%) \\
\end{array}$ & $\begin{array}{c}\text { as } \% \\
\text { of } V^{*}\end{array}$ & $\begin{array}{l}\text { Vol. } \\
(\%)\end{array}$ & $\begin{array}{c}\text { Prem } \\
(\%)\end{array}$ & & & \\
\hline Aaa & 13.1 & 5.37 & 0.77 & 100.00 & 34.06 & 4.74 & 36.89 & 63 & 58.6 \\
\hline $\mathrm{Aa}$ & 21.2 & 5.60 & 0.99 & 96.79 & 29.23 & 4.51 & 34.46 & 91 & 37.9 \\
\hline $\mathrm{A}$ & 32.0 & 5.99 & 1.55 & 87.72 & 25.25 & 4.17 & 38.50 & 123 & 31.3 \\
\hline Baa & 43.3 & 6.55 & 4.39 & 87.29 & 25.05 & 3.92 & 59.46 & 194 & 30.6 \\
\hline $\mathrm{Ba}$ & 53.5 & 7.30 & 20.63 & 100.00 & 36.00 & 4.68 & 165.70 & 320 & 51.8 \\
\hline $\mathrm{B}$ & 65.7 & 8.76 & 43.91 & 100.00 & 52.33 & 6.68 & 408.38 & 470 & 86.9 \\
\hline
\end{tabular}

Table 4 reports calibration results and calculated credit yield spreads using the Leland and Toft (1996) model. The setup is otherwise identical to that of the base case. For bonds of each credit rating, the model calibrated to match the target initial leverage ratio (column 2), equity premium (column 3), and cumulative default probability over 10 years (column 4) is shown to have the implied asset volatility and the asset risk premium given in columns 6 and 7 . The bond recovery rate given default is assumed to be the lower of $51.31 \%$ of the face value or $100 \%$ of the firm value at default $\left(V^{*}\right)$. Bond recovery as a percentage of the firm value at default, $V^{*}$, is shown in column 5 . The credit yield spreads calculated from such calibrated models (column 8) are also shown as a percentage (column 10) of historically observed yield spreads for the bonds (column 9). Parameter choices are as follows: the coupon rate is $8.13 \%$; the asset payout ratio $\delta=6 \%$; and the interest rate is constant at $8 \%$.

Note that the higher credit yield spreads here are due to the fact that the version of LT model that we implement here assumes an infinite bond maturity, even though we calibrate the model to match only the 10-year cumulative default probability. In fact, the credit yield spreads for 10-year bonds generated by such a calibrated model are indeed very close to those shown in the base case. See section 4.3 for more details. 


\section{Table 5: Strategic Default with the Anderson-Sundaresan- Tychon and Mella-Barral-Perraudin Models}

\begin{tabular}{|c|c|c|c|c|c|c|c|c|c|c|}
\hline (1) & (2) & $(3)$ & (4) & (5) & (6) & $(7)$ & (8) & (9) & (10) & (11) \\
\hline & \multicolumn{3}{|c|}{ Target } & \multicolumn{4}{|c|}{ Implied } & & & \\
\hline & & & Cum. & Fixed & Prop. & & Asset & Calc & Avg & $\%$ of \\
\hline Credit & Leverage & Equity & Default & Bkrptcy & Bkrptcy & Asset & Risk & Credit & Yield & Spread \\
\hline Rating & $\begin{array}{c}\text { Ratio } \\
(\%)\end{array}$ & $\begin{array}{l}\text { Prem } \\
(\%)\end{array}$ & $\begin{array}{l}\text { Prob. } \\
(\%)\end{array}$ & $\begin{array}{c}\text { Cost } \\
\left(K / V_{0}\right)\end{array}$ & $\begin{array}{c}\text { Cost } \\
(1-\omega)\end{array}$ & $\begin{array}{l}\text { Vol. } \\
(\%)\end{array}$ & $\begin{array}{c}\text { Prem } \\
(\%)\end{array}$ & $\begin{array}{l}\text { Sprd. } \\
\text { (bp) }\end{array}$ & $\begin{array}{l}\text { Sprd. } \\
\text { (bp) }\end{array}$ & $\begin{array}{l}\text { due to } \\
\text { Default }\end{array}$ \\
\hline Aaa & 13.1 & 5.38 & 0.77 & 2.40 & 46.36 & 25.00 & 4.73 & 31.22 & 63 & 49.5 \\
\hline $\mathrm{Aa}$ & 21.2 & 5.60 & 0.99 & 7.01 & 24.41 & 22.00 & 4.52 & 33.33 & 91 & 36.6 \\
\hline A & 32.0 & 5.99 & 1.55 & 17.23 & 0.69 & 19.00 & 4.26 & 39.48 & 123 & 32.1 \\
\hline Baa & 43.3 & 6.55 & 4.39 & 27.00 & 0.00 & 16.11 & 4.10 & 59.41 & 194 & 30.6 \\
\hline
\end{tabular}

Table 5 reports calibration results and calculated credit yield spreads using the AndersonSundaresan-Tychon (1996) and Mella-Barral and Perraudin (1997) models. The setup is otherwise identical to that of the base case. For bonds of each credit rating, the model calibrated to match the target initial leverage ratio (column 2), equity premium (column 3 ), and cumulative default probability over 10 years (column 4 ) is shown to have the implied asset volatility and the asset risk premium given in columns 7 and 8 . Columns 5 and 6 show, respectively, the fixed bankruptcy cost $(K)$ (as a percentage of the firm's initial asset value) and the proportional bankruptcy cost $(1-\omega)$ (as a percentage of the firm's asset value at the endogenously determined default boundary $V^{*}$ ) that the model can assume in order to achieve the desired bond recovery rate of $51.31 \%$ (of face value). The credit yield spreads calculated from such calibrated models (column 9) are also shown as a percentage (column 11) of historically observed yield spreads for the bonds (column 10). Parameter choices are as follows: the coupon rate is $8.13 \%$; the asset payout ratio $\delta=6 \%$; and the interest rate is constant at $8 \%$.

Junk bond results are not available because we are not able to calibrate such model to match junk bond target parameters, especially the initial leverage ratio.

Note that the higher credit yield spreads here are due to the fact that the AST-MBP models assume an infinite bond maturity, even though we calibrate the model to match only the 10-year cumulative default probability. In fact, the credit yield spreads for 10-year bonds generated by such a calibrated model are indeed very close to those shown in the base case. See section 4.4 for more details. 


\section{Table 6: Mean-Reverting Leverage Ratios with the Collin- Dufresne and Goldstein Model}

Panel A: Maturity $=10$ years

\begin{tabular}{|c|c|c|c|c|c|c|c|c|}
\hline (1) & (2) & (3) & (4) & (5) & (6) & (7) & (8) & (9) \\
\hline & \multicolumn{3}{|c|}{ Target } & \multicolumn{2}{|c|}{ Implied } & \multirow[b]{2}{*}{$\begin{array}{c}\text { Calc } \\
\text { Credit }\end{array}$} & \multirow[b]{2}{*}{$\begin{array}{c}\text { Avg } \\
\text { Yield }\end{array}$} & \multirow[b]{2}{*}{$\begin{array}{c}\% \text { of } \\
\text { Spread }\end{array}$} \\
\hline Credit & Leverage & Equity & $\begin{array}{c}\text { Cum. } \\
\text { Default }\end{array}$ & Asset & $\begin{array}{c}\text { Asset } \\
\text { Risk }\end{array}$ & & & \\
\hline Rating & $\begin{array}{c}\text { Ratio } \\
(\%) \\
\end{array}$ & $\begin{array}{c}\text { Prem } \\
(\%) \\
\end{array}$ & $\begin{array}{c}\text { Prob. } \\
(\%) \\
\end{array}$ & $\begin{array}{l}\text { Vol. } \\
(\%)\end{array}$ & $\begin{array}{c}\text { Prem } \\
(\%) \\
\end{array}$ & $\begin{array}{c}\text { Spread } \\
\text { (bps) }\end{array}$ & $\begin{array}{c}\text { Spread } \\
\text { (bps) }\end{array}$ & $\begin{array}{c}\text { due to } \\
\text { Default }\end{array}$ \\
\hline Aaa & 7.8 & 5.38 & 0.77 & 25.9 & 4.96 & 11.4 & 63 & 18.2 \\
\hline $\mathrm{Aa}$ & 12.7 & 5.60 & 0.99 & 24.9 & 4.91 & 14.9 & 91 & 16.4 \\
\hline $\mathrm{A}$ & 19.2 & 5.99 & 1.55 & 24.5 & 4.89 & 22.5 & 123 & 18.3 \\
\hline Baa & 26.0 & 6.55 & 4.39 & 26.3 & 5.00 & 52.3 & 194 & 26.9 \\
\hline $\mathrm{Ba}$ & 32.1 & 7.30 & 20.63 & 32.9 & 5.46 & 182.7 & 320 & 57.1 \\
\hline $\mathrm{B}$ & 39.4 & 8.76 & 43.91 & 39.9 & 6.43 & 371.6 & 470 & 79.1 \\
\hline \multicolumn{9}{|c|}{ Panel B: Maturity $=4$ years } \\
\hline Aaa & 7.8 & 5.38 & 0.04 & 25.9 & 4.95 & 0.0 & 55 & 0.1 \\
\hline $\mathrm{Aa}$ & 12.7 & 5.60 & 0.23 & 31.9 & 4.90 & 6.3 & 65 & 9.7 \\
\hline $\mathrm{A}$ & 19.2 & 5.99 & 0.35 & 29.1 & 4.86 & 9.9 & 96 & 10.3 \\
\hline Baa & 26.0 & 6.55 & 1.24 & 29.6 & 4.91 & 31.1 & 158 & 19.7 \\
\hline $\mathrm{Ba}$ & 32.1 & 7.30 & 8.51 & 35.8 & 5.28 & 168.0 & 320 & 52.5 \\
\hline $\mathrm{B}$ & 39.4 & 8.76 & 23.32 & 41.8 & 6.21 & 435.3 & 470 & 92.6 \\
\hline
\end{tabular}

Table 6 reports calibration results and calculated credit yield spreads for two maturities using the Collin-Dufresne and Goldstein model, in which the firm adjusts its debt level such that the leverage ratio is mean-reverting. The setup is otherwise identical to that of the base case. For bonds of each credit rating and maturity, the model calibrated to match the target initial leverage ratio (column 2), equity premium (column 3), and cumulative default probability until bond maturity (column 4 ) is shown to have the implied asset volatility and the asset risk premium given in columns 5 and 6 . The credit yield spreads calculated from such calibrated models (column 7) are also shown as a percentage (column 9) of historically observed yield spreads for the bonds (column 8). Parameter choices are as follows: the coupon rate is $8.13 \%$; the asset payout ratio $\delta=6 \%$; the interest rate is constant at $8 \%$; the recovery rate given default is fixed at $51.31 \%$; the mean-reversion coefficient of the leverage ratio $\kappa_{\ell}=0.2$; and the long-term mean leverage ratio is $38 \%$. 


\title{
Table 7: A Counter-Cyclical Market Risk Premium
}

\author{
Panel A: Maturity $=10$ years
}

\begin{tabular}{|c|c|c|c|c|c|c|c|c|}
\hline (1) & (2) & (3) & (4) & (5) & (6) & (7) & (8) & (9) \\
\hline & \multicolumn{3}{|c|}{ Target } & \multicolumn{2}{|c|}{ Implied } & & & \\
\hline & & & Cum. & & Asset & Calc & Avg & $\%$ of \\
\hline Credit & Leverage & Equity & Default & Asset & Risk & Credit & Yield & Spread \\
\hline Rating & $\begin{array}{c}\text { Ratio } \\
(\%) \\
\end{array}$ & $\begin{array}{c}\text { Prem } \\
(\%) \\
\end{array}$ & $\begin{array}{c}\text { Prob. } \\
(\%)\end{array}$ & $\begin{array}{l}\text { Vol. } \\
(\%)\end{array}$ & $\begin{array}{c}\text { Prem } \\
(\%) \\
\end{array}$ & $\begin{array}{c}\text { Spread } \\
\text { (bps) }\end{array}$ & $\begin{array}{c}\text { Spread } \\
\text { (bps) }\end{array}$ & $\begin{array}{l}\text { due to } \\
\text { Default }\end{array}$ \\
\hline Aaa & 13.1 & 5.37 & 0.77 & 33.2 & 4.96 & 13.1 & 63 & 20.8 \\
\hline $\mathrm{Aa}$ & 21.2 & 5.60 & 0.99 & 29.4 & 4.92 & 18.2 & 91 & 20.0 \\
\hline $\mathrm{A}$ & 32.0 & 5.99 & 1.55 & 26.5 & 4.90 & 28.8 & 123 & 23.4 \\
\hline Baa & 43.3 & 6.55 & 4.39 & 26.7 & 5.04 & 65.2 & 194 & 33.6 \\
\hline $\mathrm{Ba}$ & 53.5 & 7.30 & 20.63 & 33.0 & 5.53 & 202.7 & 320 & 63.3 \\
\hline B & 65.7 & 8.76 & 43.91 & 39.9 & 6.48 & 392.9 & 470 & 83.6 \\
\hline
\end{tabular}

Panel B: Maturity $=4$ years

\begin{tabular}{ccccccccc}
\hline \hline Aaa & 13.1 & 5.38 & 0.04 & 37.1 & 4.95 & 1.6 & 55 & 3.0 \\
Aa & 21.2 & 5.60 & 0.23 & 35.3 & 4.90 & 7.9 & 65 & 12.1 \\
A & 32.0 & 5.99 & 0.35 & 30.7 & 4.86 & 12.8 & 96 & 13.4 \\
Baa & 43.3 & 6.55 & 1.24 & 29.7 & 4.93 & 38.7 & 158 & 24.5 \\
$\mathrm{Ba}$ & 53.5 & 7.30 & 8.51 & 35.0 & 5.34 & 186.1 & 320 & 58.1 \\
$\mathrm{~B}$ & 65.7 & 8.76 & 23.32 & 40.0 & 6.30 & 458.7 & 470 & 97.6 \\
\hline
\end{tabular}

Table 7 reports calibration results and calculated credit yield spreads for two maturities under the assumption that market asset risk premia are counter-cyclically time varying. The modeling and parameter setup is otherwise identical to that of the base case. For bonds of each credit rating and maturity, the model calibrated to match the target initial leverage ratio (column 2), equity premium (column 3), and cumulative default probability until bond maturity (column 4) is shown to have the implied asset volatility and the asset risk premium given in columns 5 and 6 . The credit yield spreads calculated from such calibrated models (column 7) are also shown as a percentage (column 9) of historically observed yield spreads for the bonds (column 8). Parameter choices are as follows: the coupon rate is $8.13 \%$; the asset payout ratio $\delta=6 \%$; the interest rate is constant at $8 \%$; the default boundary $V^{*}$ equals $60 \%$ of the total face value of the firms' bonds outstanding; the recovery rate given default is fixed at $51.31 \%$; and the parameters in the risk-premium process are $\kappa_{\pi}=0.202, \sigma_{\pi}=3.1 \%$, and $\rho_{\pi V}=-0.35$. 


\section{Table 8: A Model with a Jump-Diffusion Firm Value Process}

Panel A: Maturity $=10$ years

\begin{tabular}{|c|c|c|c|c|c|c|c|c|c|c|}
\hline$(1)$ & $(2)$ & $(3)$ & (4) & (5) & $(6)$ & (7) & $(8)$ & $(9)$ & $(10)$ & (11) \\
\hline \multirow{4}{*}{$\begin{array}{l}\text { Credit } \\
\text { Rating }\end{array}$} & \multicolumn{3}{|c|}{ Target } & \multicolumn{4}{|c|}{ Implied } & \multirow{4}{*}{$\begin{array}{c}\text { Calc } \\
\text { Credit } \\
\text { Sprd. } \\
\text { (bp) }\end{array}$} & \multirow{4}{*}{$\begin{array}{c}\text { Avg } \\
\text { Yield } \\
\text { Sprd. } \\
\text { (bp) }\end{array}$} & \multirow{4}{*}{$\begin{array}{l}\% \text { of } \\
\text { Sprd. } \\
\text { due to } \\
\text { default }\end{array}$} \\
\hline & \multirow{3}{*}{$\begin{array}{c}\text { Leverage } \\
\text { Ratio } \\
(\%) \\
\end{array}$} & \multirow{3}{*}{$\begin{array}{c}\text { Equity } \\
\text { Prem } \\
(\%)\end{array}$} & \multirow{3}{*}{$\begin{array}{c}\text { Cum. } \\
\text { Default } \\
\text { Prob } \\
(\%)\end{array}$} & \multirow{3}{*}{$\begin{array}{c}\text { Jump } \\
\text { Vol. } \\
(\%)\end{array}$} & \multirow{3}{*}{$\begin{array}{c}\text { Diffu. } \\
\text { Vol. } \\
(\%)\end{array}$} & \multirow{3}{*}{$\begin{array}{c}\text { Jump } \\
\text { Risk } \\
\text { Prem } \\
(\%)\end{array}$} & \multirow{3}{*}{$\begin{array}{c}\text { Asset } \\
\text { Risk } \\
\text { Prem } \\
(\%)\end{array}$} & & & \\
\hline & & & & & & & & & & \\
\hline & & & & & & & & & & \\
\hline Aaa & 13.1 & 5.37 & 0.77 & 8.20 & 31.0 & 4.96 & 4.96 & 11.0 & 63 & 17.4 \\
\hline $\mathrm{Aa}$ & 21.2 & 5.60 & 0.99 & 8.20 & 27.2 & 4.91 & 4.91 & 15.8 & 91 & 17.3 \\
\hline $\mathrm{A}$ & 32.0 & 5.99 & 1.55 & 8.20 & 24.3 & 4.90 & 4.90 & 26.1 & 123 & 21.2 \\
\hline Baa & 43.3 & 6.55 & 4.39 & 8.20 & 24.5 & 5.02 & 5.02 & 61.4 & 194 & 31.7 \\
\hline $\mathrm{Ba}$ & 53.5 & 7.30 & 20.63 & 8.20 & 31.3 & 5.51 & 5.51 & 198.9 & 320 & 62.2 \\
\hline $\mathrm{B}$ & 65.7 & 8.98 & 43.91 & 8.20 & 38.7 & 6.48 & 6.48 & 394.9 & 470 & 84.0 \\
\hline
\end{tabular}

Panel B: Maturity $=4$ years

\begin{tabular}{ccccccccccc}
\hline \hline Aaa & 13.1 & 5.37 & 0.04 & 8.20 & 36.0 & 4.95 & 4.95 & 1.7 & 55 & 3.1 \\
Aa & 21.2 & 5.60 & 0.23 & 8.20 & 33.5 & 4.90 & 4.90 & 6.8 & 65 & 10.5 \\
A & 32.0 & 5.99 & 0.35 & 8.20 & 28.6 & 4.86 & 4.86 & 11.4 & 96 & 11.9 \\
Baa & 43.3 & 6.55 & 1.24 & 8.20 & 27.7 & 4.93 & 4.93 & 35.9 & 158 & 22.7 \\
Ba & 53.5 & 7.30 & 8.51 & 8.20 & 33.4 & 5.32 & 5.32 & 180.7 & 320 & 56.5 \\
B & 65.7 & 8.98 & 23.32 & 8.20 & 38.9 & 6.46 & 6.46 & 463.0 & 470 & 98.5 \\
\hline
\end{tabular}

Panel C: Maturity = 1 year

\begin{tabular}{ccccccccc}
\hline \hline $\mathrm{Aa}$ & 21.2 & 5.60 & 0.03 & 8.20 & 54.0 & 4.89 & 4.89 & 1.8 \\
$\mathrm{~A}$ & 32.0 & 5.99 & 0.01 & 8.20 & 44.0 & 4.84 & 4.84 & 1.1 \\
$\mathrm{Baa}$ & 43.3 & 6.55 & 0.12 & 8.20 & 40.6 & 4.86 & 4.86 & 9.9 \\
$\mathrm{Ba}$ & 53.5 & 7.30 & 1.29 & 8.20 & 43.9 & 5.06 & 5.06 & 90.5 \\
$\mathrm{~B}$ & 65.7 & 8.76 & 6.47 & 8.20 & 47.9 & 5.80 & 5.80 & 427.1 \\
\hline
\end{tabular}

Table 8 reports calibration results and calculated credit yield spreads for three maturities using the model with a double-exponential jump-diffusion firm asset value process. The model and parameter setup is otherwise identical to that of the base case. For bonds of 
each credit rating and maturity, the model calibrated to match the target initial leverage ratio (column 2), equity premium (column 3), and cumulative default probability until bond maturity (column 4) is shown to have the implied asset diffusion volatility and the asset risk premium given in columns 6 and 8 . The credit yield spreads calculated from such calibrated models (column 9) are also shown as a percentage (column 11) of historically observed yield spreads for the bonds (column 10). The jump process under the real probability measure is calibrated to be roughly consistent with the empirical results in Anderson, Benzoni, and Lund (2001), with parameters given by $\lambda=3, p_{u}=p_{d}=0.5, \eta_{u}=\eta_{d}=30$, and a jump volatility given by column 5 . The real to risk-neutral probability transformation is assumed to be such that all of the asset risk premium is due to the jump risk premium (shown in column 7). Other parameter choices are as follows: the coupon rate is $8.13 \%$; the asset payout ratio $\delta=6 \%$; the interest rate is constant at $8 \%$; the default boundary $V^{*}$ equals $60 \%$ of the total face value of the firms' bonds outstanding; and the recovery rate given default is fixed at $51.31 \%$. 


\section{Table 9: Extreme Parameters in the Jump-Diffusion Model}

Panel A: Maturity $=10$ years

\begin{tabular}{|c|c|c|c|c|c|c|c|c|c|c|}
\hline (1) & $(2)$ & $(3)$ & (4) & $(5)$ & $(6)$ & (7) & $(8)$ & $(9)$ & $(10)$ & (11) \\
\hline & \multicolumn{3}{|c|}{ Target } & \multicolumn{4}{|c|}{ Implied } & & & \\
\hline Credit & Leverage & Equity & $\begin{array}{c}\text { Cum. } \\
\text { Default }\end{array}$ & Jump & Diffu. & $\begin{array}{c}\text { Jump } \\
\text { Risk }\end{array}$ & $\begin{array}{l}\text { Asset } \\
\text { Risk }\end{array}$ & $\begin{array}{c}\text { Calc } \\
\text { Credit }\end{array}$ & $\begin{array}{l}\text { Avg } \\
\text { Yield }\end{array}$ & $\begin{array}{c}\% \text { of } \\
\text { Spread }\end{array}$ \\
\hline Rating & $\begin{array}{c}\text { Ratio } \\
(\%) \\
\end{array}$ & $\begin{array}{c}\text { Prem } \\
(\%) \\
\end{array}$ & $\begin{array}{c}\text { Prob } \\
(\%)\end{array}$ & $\begin{array}{l}\text { Vol. } \\
(\%)\end{array}$ & $\begin{array}{l}\text { Vol. } \\
(\%)\end{array}$ & $\begin{array}{c}\text { Prem } \\
(\%) \\
\end{array}$ & $\begin{array}{c}\text { Prem } \\
(\%)\end{array}$ & $\begin{array}{c}\text { Spread } \\
(\mathrm{bp})\end{array}$ & $\begin{array}{c}\text { Spread } \\
(\mathrm{bp})\end{array}$ & $\begin{array}{l}\text { due to } \\
\text { default }\end{array}$ \\
\hline Aaa & 13.1 & 5.37 & 0.77 & 10.35 & 30.8 & 5.00 & 5.01 & 53.1 & 63 & 84.3 \\
\hline $\mathrm{Aa}$ & 21.2 & 5.60 & 0.99 & 10.35 & 26.9 & 5.01 & 5.01 & 72.6 & 91 & 79.8 \\
\hline $\mathrm{A}$ & 32.0 & 5.99 & 1.55 & 10.35 & 24.0 & 5.08 & 5.08 & 101.8 & 123 & 82.8 \\
\hline Baa & 43.3 & 6.55 & 4.39 & 10.35 & 24.6 & 5.31 & 5.31 & 154.5 & 194 & 79.7 \\
\hline $\mathrm{Ba}$ & 53.5 & 7.23 & 20.63 & 10.35 & 30.9 & 5.24 & 5.25 & 263.2 & 320 & 82.3 \\
\hline B & 65.7 & 8.71 & 43.91 & 10.35 & 38.9 & 6.70 & 6.70 & 456.0 & 470 & 97.0 \\
\hline
\end{tabular}

Panel B: Maturity $=4$ years

\begin{tabular}{ccccccccccc}
\hline \hline Aaa & 13.1 & 5.37 & 0.04 & 10.35 & 35.1 & 4.98 & 4.98 & 33.9 & 55 & 61.7 \\
Aa & 21.2 & 5.60 & 0.23 & 10.35 & 32.9 & 4.98 & 4.98 & 61.6 & 65 & 94.8 \\
A & 32.0 & 5.99 & 0.35 & 10.35 & 27.9 & 5.04 & 5.04 & 91.0 & 96 & 94.8 \\
Baa & 43.3 & 6.55 & 1.24 & 10.35 & 27.4 & 5.26 & 5.26 & 148.7 & 158 & 94.1 \\
Ba & 53.5 & 7.23 & 8.51 & 10.35 & 33.5 & 5.71 & 5.71 & 305.0 & 320 & 95.3 \\
B & 65.7 & 8.71 & 23.32 & 10.35 & 39.0 & 6.71 & 6.72 & 570.4 & 470 & 121.4 \\
\hline
\end{tabular}

Panel C: Maturity $=1$ year

\begin{tabular}{ccccccccc}
\hline \hline $\mathrm{Aa}$ & 21.2 & 5.60 & 0.03 & 10.35 & 53.5 & 4.95 & 4.95 & 48.9 \\
$\mathrm{~A}$ & 32.0 & 5.99 & 0.01 & 10.35 & 23.6 & 4.94 & 4.94 & 50.4 \\
$\mathrm{Baa}$ & 43.3 & 6.55 & 0.12 & 10.35 & 39.2 & 5.17 & 5.17 & 124.4 \\
$\mathrm{Ba}$ & 53.5 & 7.30 & 1.29 & 10.35 & 43.8 & 5.61 & 5.61 & 257.5 \\
$\mathrm{~B}$ & 65.7 & 8.42 & 6.47 & 10.35 & 48.1 & 6.35 & 6.35 & 621.5 \\
\hline
\end{tabular}

Table 9 reports calibration results and calculated credit yield spreads for three maturities by using an extreme set of parameter choices in the model with a double-exponential jumpdiffusion firm asset value process. The model and parameter setup is otherwise identical to 
that of the base case. For bonds of each credit rating and maturity, the model calibrated to match the target initial leverage ratio (column 2), equity premium (column 3), and cumulative default probability until bond maturity (column 4) is shown to have the implied asset diffusion volatility and the asset risk premium given in columns 6 and 8 . The credit yield spreads calculated from such calibrated models (column 9) are also shown as a percentage (column 11) of historically observed yield spreads for the bonds (column 10). The jump process under the real probability measure is taken to be extreme, with parameters given by $\lambda=0.1, p_{u}=p_{d}=0.5, \eta_{u}=\eta_{d}=5$, and a jump volatility given by column 5 . The real to risk-neutral probability transformation is assumed to be such that all of the asset risk premium is due to the jump risk premium (shown in column 7). Other parameter choices are as follows: the coupon rate is $8.13 \%$; the asset payout ratio $\delta=6 \%$; the interest rate is constant at $8 \%$; the default boundary $V^{*}$ equals $60 \%$ of the total face value of the firms' bonds outstanding; and the recovery rate given default is fixed at $51.31 \%$. 


\section{Table 10: Sensitivity Analysis: Equity Premium Higher by $2 \%$}

Panel A: Maturity $=10$ years

\begin{tabular}{|c|c|c|c|c|c|c|c|c|}
\hline (1) & (2) & (3) & (4) & (5) & (6) & (7) & (8) & (9) \\
\hline & \multicolumn{3}{|c|}{ Target } & \multicolumn{2}{|c|}{ Implied } & & & \\
\hline Credit & Leverage & Equity & $\begin{array}{c}\text { Cum. } \\
\text { Default }\end{array}$ & Asset & $\begin{array}{c}\text { Asset } \\
\text { Risk }\end{array}$ & $\begin{array}{c}\text { Calc } \\
\text { Credit }\end{array}$ & $\begin{array}{c}\text { Avg } \\
\text { Yield }\end{array}$ & $\begin{array}{c}\% \text { of } \\
\text { Spread }\end{array}$ \\
\hline Rating & $\begin{array}{c}\text { Ratio } \\
(\%)\end{array}$ & $\begin{array}{c}\text { Prem } \\
(\%)\end{array}$ & $\begin{array}{c}\text { Prob. } \\
(\%)\end{array}$ & $\begin{array}{l}\text { Vol. } \\
(\%)\end{array}$ & $\begin{array}{c}\text { Prem } \\
(\%)\end{array}$ & $\begin{array}{c}\text { Spread } \\
\text { (bps) }\end{array}$ & $\begin{array}{c}\text { Spread } \\
\text { (bps) }\end{array}$ & $\begin{array}{l}\text { due to } \\
\text { Default }\end{array}$ \\
\hline Aaa & 13.1 & 7.38 & 0.77 & 33.5 & 6.81 & 14.1 & 63 & 22.3 \\
\hline $\mathrm{Aa}$ & 21.2 & 7.60 & 0.99 & 29.8 & 6.67 & 19.8 & 91 & 21.8 \\
\hline $\mathrm{A}$ & 32.0 & 7.99 & 1.55 & 27.0 & 6.54 & 31.8 & 123 & 25.8 \\
\hline Baa & 43.3 & 8.55 & 4.39 & 27.3 & 6.56 & 71.4 & 194 & 36.8 \\
\hline $\mathrm{Ba}$ & 53.5 & 9.30 & 20.63 & 34.0 & 7.03 & 218.0 & 320 & 68.1 \\
\hline B & 65.7 & 10.76 & 43.91 & 41.3 & 7.97 & 415.5 & 470 & 88.4 \\
\hline
\end{tabular}

Panel B: Maturity $=4$ years

\begin{tabular}{ccccccccc}
\hline \hline Aaa & 13.1 & 7.38 & 0.04 & 37.0 & 6.80 & 1.6 & 55 & 2.8 \\
Aa & 21.2 & 7.60 & 0.23 & 35.3 & 6.64 & 7.7 & 65 & 11.9 \\
A & 32.0 & 7.99 & 0.35 & 30.6 & 6.48 & 12.7 & 96 & 13.2 \\
Baa & 43.3 & 8.55 & 1.24 & 29.7 & 6.42 & 39.1 & 158 & 24.8 \\
Ba & 53.5 & 9.30 & 8.51 & 35.3 & 6.77 & 193.3 & 320 & 60.4 \\
B & 65.7 & 10.76 & 23.32 & 40.7 & 7.71 & 477.8 & 470 & 101.7 \\
\hline
\end{tabular}

Table 10 reports calibration results and calculated credit yield spreads for two maturities for the case in which the equity premia for all firms are $2 \%$ higher than those assumed in the base case. The setup is otherwise identical to that of the base case. For bonds of each credit rating and maturity, the model calibrated to match the target initial leverage ratio (column 2), equity premium (column 3), and cumulative default probability until bond maturity (column 4) is shown to have the implied asset volatility and the asset risk premium given in columns 5 and 6 . The credit yield spreads calculated from such calibrated models (column 7) are also shown as a percentage (column 9) of historically observed yield spreads for the bonds (column 8). Other parameter choices are as follows: the coupon rate is $8.162 \%$; asset payout ratio $\delta=6 \%$; the interest rate is constant at $r=8 \%$, the default boundary $V^{*}$ equals $60 \%$ of the total face value of the firms' bonds outstanding; and the recovery rate given default is fixed at $51.31 \%$. 


\title{
Table 11: Sensitivity Aanalysis: Different Default Boundaries
}

\author{
Panel A: Default boundary $V^{*}=F$
}

\begin{tabular}{|c|c|c|c|c|c|c|c|c|}
\hline (1) & $(2)$ & (3) & $(4)$ & (5) & $(6)$ & (7) & (8) & $(9)$ \\
\hline & \multicolumn{3}{|c|}{ Target } & \multicolumn{2}{|c|}{ Implied } & & & \\
\hline & & & Cum. & & Asset & Calc & Avg & $\%$ of \\
\hline Credit & Leverage & Equity & Default & Asset & Risk & Credit & Yield & Spread \\
\hline Rating & $\begin{array}{c}\text { Ratio } \\
(\%) \\
\end{array}$ & $\begin{array}{c}\text { Prem } \\
(\%) \\
\end{array}$ & $\begin{array}{c}\text { Prob. } \\
(\%) \\
\end{array}$ & $\begin{array}{l}\text { Vol. } \\
(\%)\end{array}$ & $\begin{array}{c}\text { Prem } \\
(\%) \\
\end{array}$ & $\begin{array}{c}\text { Spread } \\
\text { (bps) }\end{array}$ & $\begin{array}{c}\text { Spread } \\
\text { (bps) }\end{array}$ & $\begin{array}{l}\text { due to } \\
\text { Default }\end{array}$ \\
\hline Aaa & 13.1 & 5.38 & 0.77 & 27.2 & 4.69 & 11.4 & 63 & 18.0 \\
\hline $\mathrm{Aa}$ & 21.2 & 5.60 & 0.99 & 23.1 & 4.45 & 16.3 & 91 & 17.9 \\
\hline $\mathrm{A}$ & 32.0 & 5.99 & 1.55 & 19.6 & 4.17 & 26.9 & 123 & 21.9 \\
\hline Baa & 43.3 & 6.55 & 4.39 & 18.5 & 4.02 & 64.5 & 194 & 33.2 \\
\hline $\mathrm{Ba}$ & 53.5 & 7.30 & 20.63 & 22.1 & 4.41 & 218.7 & 320 & 68.3 \\
\hline B & 65.7 & 8.76 & 43.91 & 25.2 & 5.21 & 446.4 & 470 & 95.0 \\
\hline
\end{tabular}

Panel B: Default boundary $V^{*}=0.6 F$

\begin{tabular}{ccccccccc}
\hline \hline Aaa & 13.1 & 5.38 & 0.77 & 32.1 & 4.96 & 10.0 & 63 & 15.8 \\
Aa & 21.2 & 5.60 & 0.99 & 28.4 & 4.91 & 14.2 & 91 & 15.6 \\
A & 32.0 & 5.99 & 1.55 & 25.6 & 4.89 & 23.3 & 123 & 19.0 \\
Baa & 43.3 & 6.55 & 4.39 & 25.8 & 5.01 & 56.5 & 194 & 29.1 \\
$\mathrm{Ba}$ & 53.5 & 7.30 & 20.63 & 32.4 & 5.48 & 192.3 & 320 & 60.1 \\
B & 65.7 & 8.76 & 43.91 & 39.5 & 6.46 & 387.8 & 470 & 82.5 \\
\hline
\end{tabular}

Table 2 reports and compares calibration results and calculated credit yield spreads for 10 -year bonds for two different default boundaries, with $V^{*}$ set to be either $100 \%$ or $60 \%$ (as in the base case) of the firm's bond face value. The setup is otherwise identical to that of the base case. For bonds of each credit rating, the model calibrated to match the target initial leverage ratio (column 2), equity premium (column 3), and cumulative default probability until bond maturity (column 4 ) is shown to have the implied asset volatility and the asset risk premium given in columns 5 and 6 . The credit yield spreads calculated from such calibrated models (column 7) are also shown as a percentage (column 9) of historically observed yield spreads for the bonds (column 8). Other parameter choices are as follows: the coupon rate is $8.162 \%$; the asset payout ratio $\delta=6 \%$; the interest rate is constant at $r=8 \%$, and the recovery rate given default is fixed at $51.31 \%$. 


\section{Table 12: Sensitivity Analysis: Different Leverage Ratios}

$$
\text { Panel A: Leverage ratio }=\text { Lower bound of base case range }
$$

\begin{tabular}{|c|c|c|c|c|c|c|c|c|}
\hline$(1)$ & $(2)$ & $(3)$ & (4) & $(5)$ & $(6)$ & $(7)$ & $(8)$ & $(9)$ \\
\hline & \multicolumn{3}{|c|}{ Target } & \multicolumn{2}{|c|}{ Implied } & & & \\
\hline & & & Cum. & & $\begin{array}{l}\text { Asset } \\
\text { Rick }\end{array}$ & Calc & $\begin{array}{l}\text { Avg } \\
\text { Yiold }\end{array}$ & $\%$ of \\
\hline Credit & Leverage & Equity & Default & Asset & Risk & Credit & Yield & Spread \\
\hline Rating & $\begin{array}{c}\text { Ratio } \\
(\%)\end{array}$ & $\begin{array}{c}\text { Prem } \\
(\%)\end{array}$ & $\begin{array}{c}\text { Prob. } \\
(\%)\end{array}$ & $\begin{array}{l}\text { Vol. } \\
(\%)\end{array}$ & $\begin{array}{c}\text { Prem } \\
(\%)\end{array}$ & $\begin{array}{c}\text { Spread } \\
(\mathrm{bps})\end{array}$ & $\begin{array}{c}\text { Spread } \\
\text { (bps) }\end{array}$ & $\begin{array}{l}\text { due to } \\
\text { Default }\end{array}$ \\
\hline Aaa & 9.0 & 5.38 & 0.77 & 35.4 & 5.09 & 9.2 & 63 & 14.6 \\
\hline $\mathrm{Aa}$ & 17.1 & 5.60 & 0.99 & 30.5 & 5.04 & 13.4 & 91 & 14.7 \\
\hline $\mathrm{A}$ & 26.6 & 5.99 & 1.55 & 27.6 & 5.07 & 22.2 & 123 & 18.1 \\
\hline Baa & 37.6 & 6.55 & 4.39 & 27.7 & 5.20 & 54.7 & 194 & 28.2 \\
\hline $\mathrm{Ba}$ & 48.4 & 7.30 & 20.63 & 34.1 & 5.65 & 188.7 & 320 & 59.0 \\
\hline $\mathrm{B}$ & 59.6 & 8.76 & 43.91 & 41.8 & 6.66 & 381.2 & 470 & 81.1 \\
\hline
\end{tabular}

Panel B: Leverage ratio $=$ Upper bound of base case range

\begin{tabular}{ccccccccc}
\hline \hline Aaa & 17.1 & 5.38 & 0.77 & 29.6 & 4.83 & 10.7 & 63 & 16.9 \\
Aa & 26.6 & 5.60 & 0.99 & 26.1 & 4.74 & 15.1 & 91 & 16.5 \\
A & 37.6 & 5.99 & 1.55 & 23.8 & 4.70 & 24.4 & 123 & 19.8 \\
Baa & 48.4 & 6.55 & 4.39 & 24.3 & 4.83 & 58.1 & 194 & 29.9 \\
Ba & 59.6 & 7.30 & 20.63 & 30.4 & 5.29 & 196.5 & 320 & 61.4 \\
B & 71.8 & 8.76 & 43.91 & 37.4 & 6.27 & 394.5 & 470 & 83.9 \\
\hline
\end{tabular}

Table 12 reports results for 10 -year bonds for two initial leverage ratios. For each credit rating, the initial leverage ratio is set to be either the lower or upper bound of the base case range, with the lower (upper) bound defined as the average between the base case initial average ratios for the credit rating and for the adjacent higher (lower) rating. (Take A-rated bonds, for example, where the lower (upper) bound is the average between $31.98 \%$ and $21.18 \%(43.28 \%)$ ).) The setup is otherwise identical to that of the base case. For bonds of each credit rating, the model calibrated to match the target initial leverage ratio (column 2), equity premium (column 3), and cumulative default probability until bond maturity (column 4) is shown to have the implied asset volatility and the asset risk premium given in columns 5 and 6 . The credit yield spreads calculated from such calibrated models (column 7) are also shown as a percentage (column 9) of historically observed yield spreads for the bonds (column 8). Other parameter choices are as follows: the coupon rate is $8.162 \%$; the asset payout ratio $\delta=6 \%$; the interest rate is constant at $r=8 \%$, the default boundary $V^{*}$ equals $60 \%$ of the total face value of the firms' bonds outstanding; and the recovery rate given default is fixed at $51.31 \%$. 


\section{Table 13: Sensitivity Aanlysis: Different Asset Payout Ratios}

$$
\text { Panel A: Payout ratio } \delta=0
$$

\begin{tabular}{|c|c|c|c|c|c|c|c|c|}
\hline (1) & (2) & (3) & (4) & (5) & (6) & (7) & (8) & (9) \\
\hline & \multicolumn{3}{|c|}{ Target } & \multicolumn{2}{|c|}{ Implied } & \multirow{3}{*}{$\begin{array}{c}\text { Calc } \\
\text { Credit }\end{array}$} & \multirow{3}{*}{$\begin{array}{c}\text { Avg } \\
\text { Yield }\end{array}$} & \multirow{3}{*}{$\begin{array}{c}\% \text { of } \\
\text { Spread }\end{array}$} \\
\hline & & & Cum. & & Asset & & & \\
\hline Credit & Leverage & Equity & Default & Asset & Risk & & & \\
\hline Rating & Ratio & Prem & Prob. & Vol. & Prem & Spread & Spread & due to \\
\hline & & & & & & & & \\
\hline Aaa & 13.1 & 5.38 & 0.77 & 36.6 & 4.96 & 8.8 & 63 & 14.0 \\
\hline $\mathrm{Aa}$ & 21.2 & 5.60 & 0.99 & 33.1 & 4.91 & 12.2 & 91 & 13.4 \\
\hline A & 32.0 & 5.99 & 1.55 & 30.5 & 4.88 & 19.6 & 123 & 16.0 \\
\hline Baa & 43.3 & 6.55 & 4.39 & 31.1 & 4.98 & 48.8 & 194 & 25.1 \\
\hline $\mathrm{Ba}$ & 53.5 & 7.30 & 20.63 & 38.4 & 5.42 & 180.5 & 320 & 56.4 \\
\hline B & 65.7 & 8.76 & 43.91 & 46.1 & 6.38 & 377.9 & 470 & 80.4 \\
\hline
\end{tabular}

Panel B: Payout ratio $\delta=0.08$

\begin{tabular}{ccccccccc}
\hline \hline Aaa & 13.1 & 5.38 & 0.77 & 30.5 & 4.96 & 10.5 & 63 & 16.7 \\
Aa & 21.2 & 5.60 & 0.99 & 26.7 & 4.91 & 15.1 & 91 & 16.6 \\
A & 32.0 & 5.99 & 1.55 & 23.9 & 4.89 & 25.3 & 123 & 20.5 \\
Baa & 43.3 & 6.55 & 4.39 & 23.9 & 5.02 & 60.7 & 194 & 31.3 \\
Ba & 53.5 & 7.30 & 20.63 & 30.2 & 5.52 & 198.4 & 320 & 62.0 \\
B & 65.7 & 8.76 & 43.91 & 37.1 & 6.50 & 392.8 & 470 & 83.6 \\
\hline
\end{tabular}

Table 13 reports and compares calibration results and calculated credit yield spreads for 10year bonds for two different asset payout ratios: $\delta=0$, and $\delta=8 \%$. The setup is otherwise identical to that of the base case. For bonds of each credit rating, the model calibrated to match the target initial leverage ratio (column 2), equity premium (column 3), and cumulative default probability until bond maturity (column 4) is shown to have the implied asset volatility and the asset risk premium given in columns 5 and 6 . The credit yield spreads calculated from such calibrated models (column 7) are also shown as a percentage (column 9) of historically observed yield spreads for the bonds (column 8). Other parameter choices are as follows: the coupon rate is $8.162 \%$; the asset payout ratio $\delta=6 \%$; the interest rate is constant at $r=8 \%$, the default boundary $V^{*}$ equals $60 \%$ of the total face value of the firms' bonds outstanding; and the recovery rate given default is fixed at $51.31 \%$. 


\title{
Table 14: Sensitivity Analysis: Target Default Probability Higher by Half
}

\author{
Panel A: Maturity $=10$ years
}

\begin{tabular}{|c|c|c|c|c|c|c|c|c|}
\hline (1) & (2) & (3) & (4) & (5) & (6) & (7) & $(8)$ & $(9)$ \\
\hline \multirow{5}{*}{$\begin{array}{l}\text { Credit } \\
\text { Rating }\end{array}$} & \multicolumn{3}{|c|}{ Target } & \multicolumn{2}{|c|}{ Implied } & \multirow{3}{*}{$\begin{array}{c}\text { Calc } \\
\text { Credit }\end{array}$} & \multirow{3}{*}{$\begin{array}{l}\text { Avg } \\
\text { Yield }\end{array}$} & \multirow{3}{*}{$\begin{array}{c}\% \text { of } \\
\text { Spread }\end{array}$} \\
\hline & \multirow{4}{*}{$\begin{array}{c}\text { Leverage } \\
\text { Ratio } \\
(\%)\end{array}$} & \multirow{4}{*}{$\begin{array}{c}\text { Equity } \\
\text { Prem } \\
(\%)\end{array}$} & \multirow{4}{*}{$\begin{array}{c}\text { Cum. } \\
\text { Default } \\
\text { Prob. } \\
(\%)\end{array}$} & \multirow{4}{*}{$\begin{array}{c}\text { Asset } \\
\text { Vol. } \\
(\%)\end{array}$} & \multirow{2}{*}{$\begin{array}{l}\text { Asset } \\
\text { Risk }\end{array}$} & & & \\
\hline & & & & & & & & \\
\hline & & & & & Prem & Spread & Spread & due to \\
\hline & & & & & $(\%)$ & (bps) & (bps) & Default \\
\hline Aaa & 13.1 & 5.38 & 1.16 & 33.4 & 4.96 & 13.6 & 63 & 21.6 \\
\hline $\mathrm{Aa}$ & 21.2 & 5.60 & 1.49 & 29.6 & 4.92 & 19.1 & 91 & 21.0 \\
\hline A & 32.0 & 5.99 & 2.33 & 26.9 & 4.90 & 31.1 & 123 & 25.3 \\
\hline Baa & 43.3 & 6.55 & 6.59 & 27.6 & 5.05 & 75.2 & 194 & 38.7 \\
\hline $\mathrm{Ba}$ & 53.5 & 7.30 & 30.95 & 36.9 & 5.59 & 263.6 & 320 & 82.4 \\
\hline B & 65.7 & 8.76 & 65.86 & 51.5 & 6.63 & 558.0 & 470 & 118.7 \\
\hline
\end{tabular}

Panel B: Maturity $=4$ years

\begin{tabular}{ccccccccc}
\hline \hline Aaa & 13.1 & 5.38 & 0.06 & 37.1 & 4.95 & 1.6 & 55 & 3.0 \\
Aa & 21.2 & 5.60 & 0.34 & 35.6 & 4.90 & 8.5 & 65 & 13.0 \\
A & 32.0 & 5.99 & 0.53 & 30.9 & 4.86 & 13.8 & 96 & 14.4 \\
Baa & 43.3 & 6.55 & 1.86 & 30.4 & 4.93 & 44.6 & 158 & 28.2 \\
Ba & 53.5 & 7.30 & 12.76 & 37.6 & 5.38 & 242.7 & 320 & 75.8 \\
B & 65.7 & 8.76 & 34.98 & 46.5 & 6.44 & 636.0 & 470 & 135.3 \\
\hline
\end{tabular}

Table 14 reports calibration results and calculated credit yield spreads for two maturities for the case in which the target default probability for each credit rating is assumed to be $150 \%$ of that in the base case (as estimated by Moody's). The setup is otherwise identical to that of the base case. For bonds of each credit rating and maturity, the model calibrated to match the target initial leverage ratio (column 2), equity premium (column 3), and cumulative default probability until bond maturity (column 4) is shown to have the implied asset volatility and the asset risk premium given in columns 5 and 6 . The credit yield spreads calculated from such calibrated models (column 7) are also shown as a percentage (column 9) of historically observed yield spreads for the bonds (column 8). Other parameter choices are as follows: the coupon rate is $8.162 \%$; the asset payout ratio $\delta=6 \%$; the interest rate is constant at $r=8 \%$, the default boundary $V^{*}$ equals $60 \%$ of the total face value of the firms' bonds outstanding; and the recovery rate given default is fixed at $51.31 \%$. 


\title{
Table 15: Sensitivity Analysis: A Lower Recovery Rate (45\%)
}

\author{
Panel A: Maturity $=10$ years
}

\begin{tabular}{|c|c|c|c|c|c|c|c|c|}
\hline (1) & $(2)$ & $(3)$ & (4) & (5) & $(6)$ & (7) & (8) & (9) \\
\hline & \multicolumn{3}{|c|}{ Target } & \multicolumn{2}{|c|}{ Implied } & & & \\
\hline & & & Cum. & & Asset & Calc & Avg & $\%$ of \\
\hline Credit & Leverage & Equity & Default & Asset & Risk & Credit & Yield & Spread \\
\hline Rating & $\begin{array}{c}\text { Ratio } \\
(\%)\end{array}$ & $\begin{array}{c}\text { Prem } \\
(\%)\end{array}$ & $\begin{array}{c}\text { Prob. } \\
(\%)\end{array}$ & $\begin{array}{l}\text { Vol. } \\
(\%)\end{array}$ & $\begin{array}{c}\text { Prem } \\
(\%)\end{array}$ & $\begin{array}{c}\text { Spread } \\
\text { (bps) }\end{array}$ & $\begin{array}{c}\text { Spread } \\
\text { (bps) }\end{array}$ & $\begin{array}{l}\text { due to } \\
\text { Default }\end{array}$ \\
\hline Aaa & 13.1 & 5.38 & 0.77 & 32.1 & 4.96 & 11.3 & 63 & 17.9 \\
\hline $\mathrm{Aa}$ & 21.2 & 5.60 & 0.99 & 28.4 & 4.91 & 16.0 & 91 & 17.6 \\
\hline $\mathrm{A}$ & 32.0 & 5.99 & 1.55 & 25.6 & 4.90 & 26.4 & 123 & 21.5 \\
\hline Baa & 43.3 & 6.55 & 4.39 & 25.8 & 5.03 & 64.3 & 194 & 33.1 \\
\hline $\mathrm{Ba}$ & 53.5 & 7.30 & 20.63 & 32.4 & 5.56 & 221.2 & 320 & 69.1 \\
\hline $\mathrm{B}$ & 65.7 & 8.76 & 43.91 & 39.7 & 6.62 & 452.7 & 470 & 96.3 \\
\hline
\end{tabular}

Panel B: Maturity $=4$ years

\begin{tabular}{ccccccccc}
\hline \hline Aaa & 13.1 & 5.38 & 0.04 & 36.2 & 4.95 & 1.3 & 55 & 2.3 \\
Aa & 21.2 & 5.60 & 0.23 & 34.4 & 4.90 & 6.8 & 65 & 10.4 \\
A & 32.0 & 5.99 & 0.35 & 29.8 & 4.86 & 11.1 & 96 & 11.6 \\
Baa & 43.3 & 6.55 & 1.24 & 28.9 & 4.92 & 36.2 & 158 & 22.9 \\
Ba & 53.5 & 7.30 & 8.51 & 34.3 & 5.34 & 196.3 & 320 & 61.4 \\
B & 65.7 & 8.76 & 23.32 & 39.7 & 6.39 & 513.4 & 470 & 109.2 \\
\hline
\end{tabular}

Table 15 reports calibration results and calculated credit yield spreads for two maturities for the case in which the target recovery rate given default is assumed to be $45 \%$ of the face amount (instead of $51.31 \%$ in the base case as estimated by Moody's). The setup is otherwise identical to that of the base case. For bonds of each credit rating and maturity, the model calibrated to match the target initial leverage ratio (column 2), equity premium (column 3), and cumulative default probability until bond maturity (column 4) is shown to have the implied asset volatility and the asset risk premium given in columns 5 and 6 . The credit yield spreads calculated from such calibrated models (column 7) are also shown as a percentage (column 9) of historically observed yield spreads for the bonds (column 8). Other parameter choices are as follows: the coupon rate is $8.162 \%$; the asset payout ratio $\delta=6 \%$; the interest rate is constant at $r=8 \%$, and the default boundary $V^{*}$ equals $60 \%$ of the total face value of the firms' bonds outstanding. 